SANDIA REPORT

SAND97-2741 • UC-700

Unlimited Release

Printed November 1997

\title{
Test Report for the INFRASOUND Prototype for a CTBT IMS Station
}

Dale R. Breding, Richard P. Kromer, Rodney W. Whitaker, Tom Sandoval

Prepared by

Sandia National Laboratories

Albuquerque, New Mexico 87185 and Livermore, California 94550

Sandia is a multiprogram laboratory operated by Sandia Corporation, a Lockheed Martin Company, for the United States Department of

Energy under Contract DE-AC04-94AL85000.

Approved for public release; further dissemination unlimited.

(1) Sandia National Laboratories
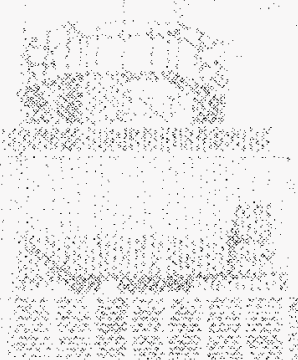

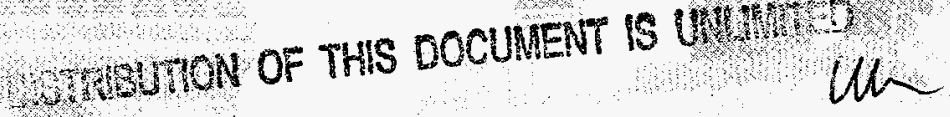

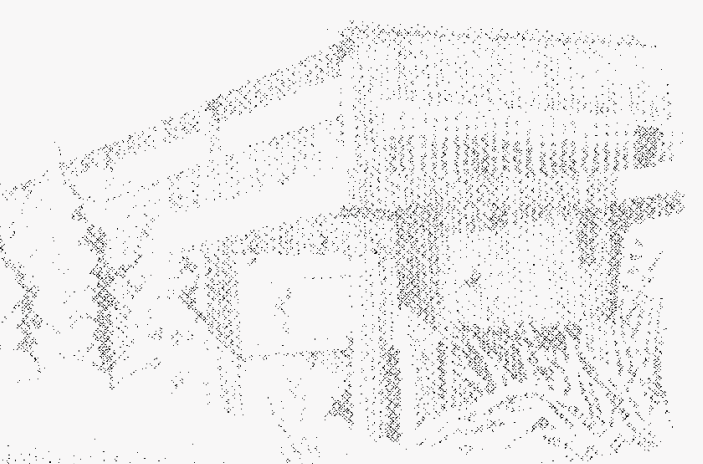
(t)
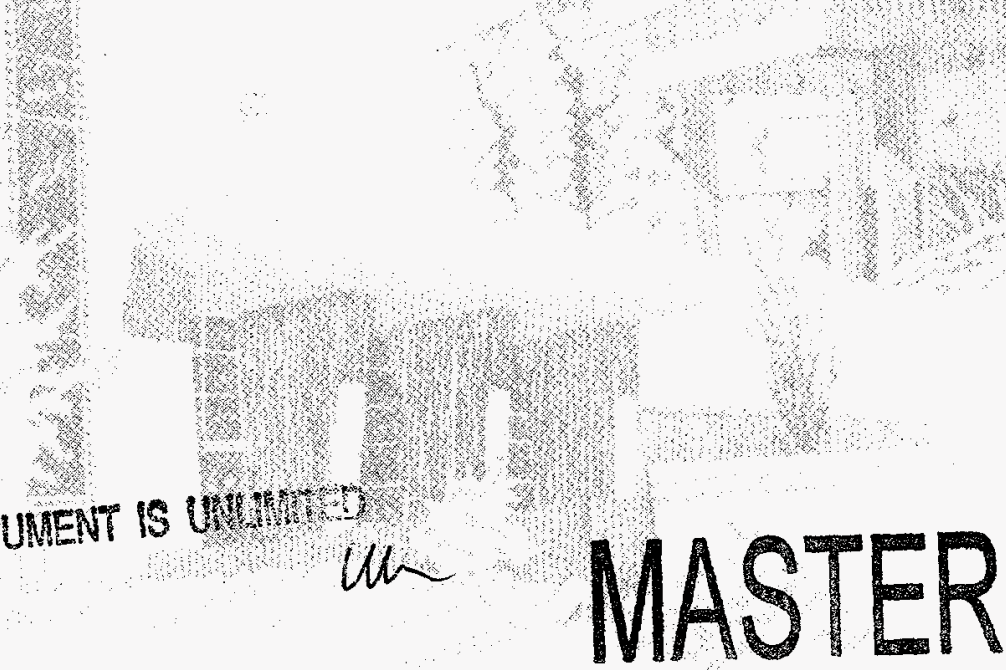


\section{DISCLAMEER}

Portions of this document may be illegible in electronic image produets. Images are produced from the best available original docemenent 


\section{DISCLAIMER}

This report was prepared as an account of work sponsored by an agency of the United States Government. Neither the United States Government nor any agency thereof, nor any of their employees, make any warranty, express or implied, or assumes any legal liability or responsibility for the accuracy, completeness, or usefulness of any information, apparatus, product, or process disclosed, or represents that its use would not infringe privately owned rights. Reference herein to any specific commercial product, process, or service by trade name, trademark, manufacturer, or otherwise does not necessarily constitute or imply its endorsement, recommendation, or favoring by the United States Government or any agency thereof. The views and opinions of authors expressed herein do not necessarily state or reflect those of the United States Government or any agency thereof. 


\title{
TEST REPORT \\ for the \\ INFRASOUND \\ Prototype
}

For a CTBT IMS Station

\author{
Dale R. Breding \\ CTBT Verification R\&D Department \\ Richard P. Kromer \\ Monitoring Technologies Department \\ Sandia National Laboratories \\ P.O. Box 5800 \\ Albuquerque, New Mexico 87185-0979 \\ Rodney W. Whitaker and Tom Sandoval \\ Los Alamos National Laboratory \\ P.O. Box 1663, MS F669 \\ Los Alamos, New Mexico 87545
}

\begin{abstract}
This document describes the results of the Comprehensive Test Ban Treaty (CTBT) Infrasound Prototype Development Test and Evaluation (DT\&E). During DT\&E the infrasound prototype was evaluated against requirements listed in the System Requirements Document (SRD) based on the Conference on Disarmament/Ad Hoc Committee on a Nuclear Test Ban/Working Papers 224 and 283 and the Preparatory Commission specifications as defined in CTBT/PC/II/1/Add.2, Appendix X, Table 5. The evaluation was conducted during a two-day period, August 6-7, 1997. The System Test Plan (STP) defined the plan and methods to test the infrasound prototype. Specific tests that were performed are detailed in the Test Procedures (TP).
\end{abstract}




\section{Acknowledgments}

The authors would like to acknowledge the efforts of the infrasound prototype development team. The team included from Los Alamos National Laboratory, Rod Whitaker, Tom Sandoval, Doug ReVelle and Tom Armstrong; from Applied Physics Incorporated, Tim McDonald; and from Sandia National Laboratories, Dale Breding, Dick Kromer, Pat Fleming, and Randy Rembold. Rod Whitaker and Dale Breding managed the project. Pat Fleming was instrumental in developing specifications and procuring the prototype data acquisition system. Dick Kromer developed the specifications for and tested the digitizer. Rod and Dick cooperated in testing the microbarograph sensor. Tim was essential in developing the microbarograph and digitizer transfer functions. Tom Sandoval contributed his system expertise, and he and Randy integrated and installed the prototype. Doug ReVelle and Tom Armstrong also assisted with the prototype installation.

Funding was provided by the U.S. Department of Energy, Office of Nonproliferation and National Security, Office of Research and Development, Comprehensive Test Ban Treaty Research and Development Program. 


\section{Table of Contents}

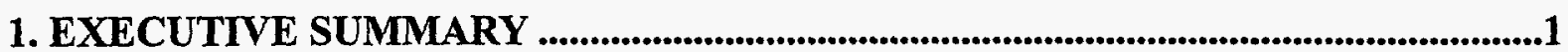

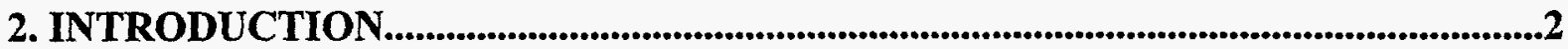

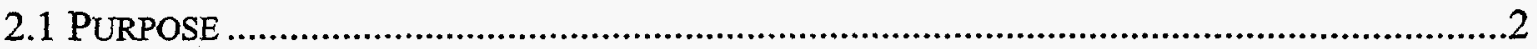

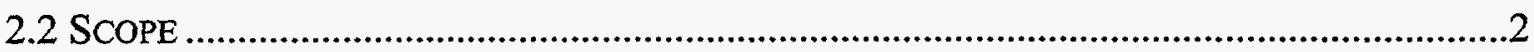

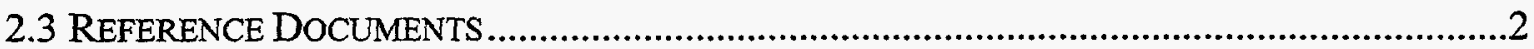

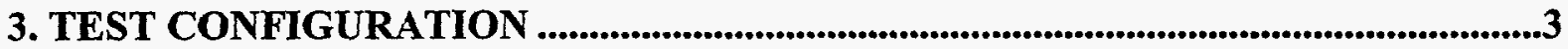

4. TEST SETUP

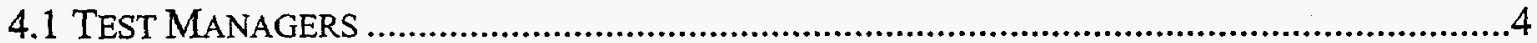

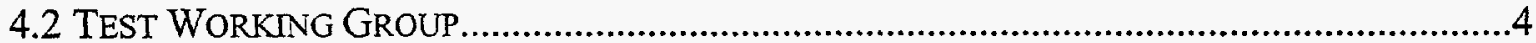

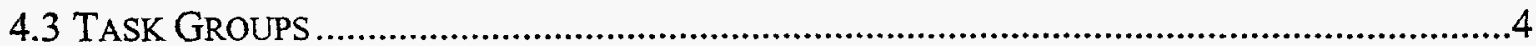

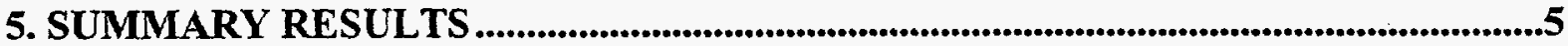

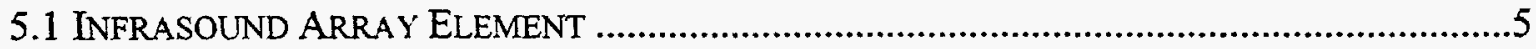

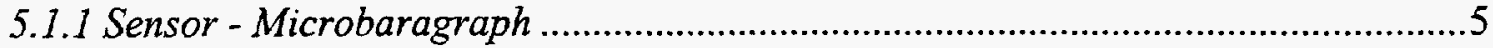

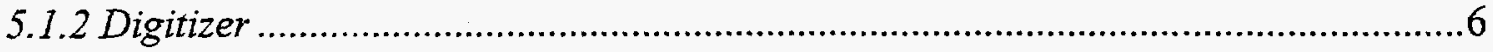

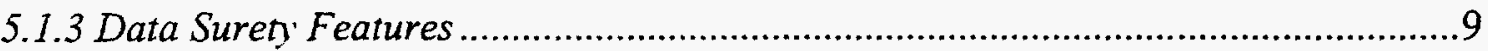

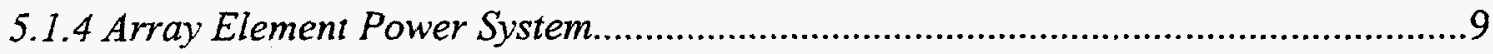

5.I.5 Meteorological Station, State of Health........................................................ 10

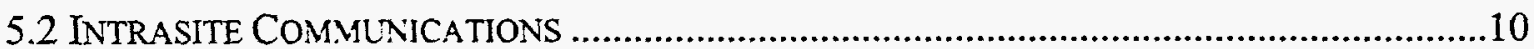

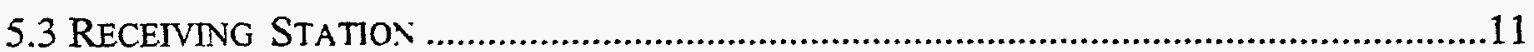

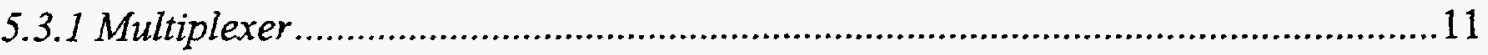

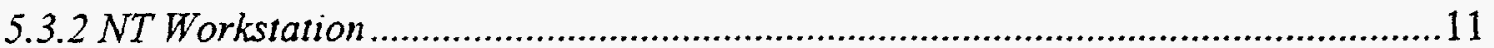

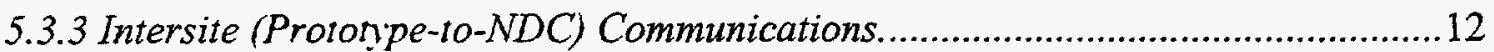

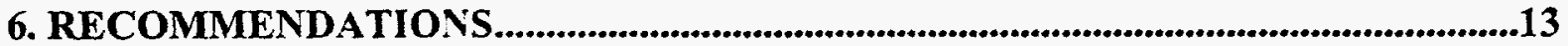

7. APPENDIX A - RELATED MEMORANDA 


\section{Table of Figures}

Figure 1. Block Diagram Of The INFrasound PrototyPe. ................................................

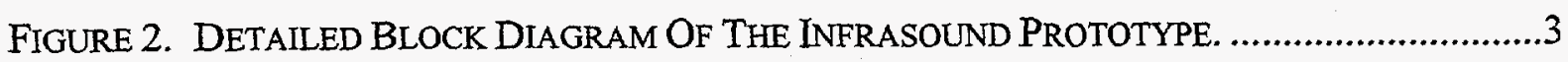

Figure 3. MEASUREd SENSOR SELF NOISE AND SPECIFIEd RESOlUtION AT $1 \mathrm{HZ}$....................6

FIGURE 4. RESOLUTION FROM A POWER SPECTRAL DENSITY PLOT. ...........................................

FigURE 5. PASSBAND AND ATTENUATION AT THE NYQUIST FREQUENCY ...............................8

\section{List of Tables}

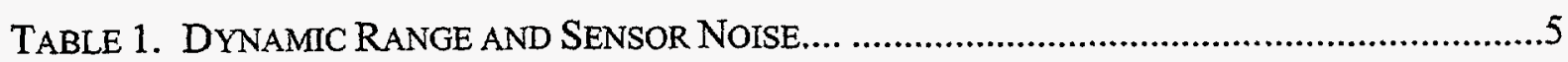

TABLE 2. SENSITIVITY ERRORS OF THE FOUR INFRASOUND DR-24 DIGITIZERS......................... 


\section{Executive Summary}

This document describes the results of the Comprehensive Test Ban Treaty (CTBT) Infrasound Prototype Development Test and Evaluation (DT\&E). During DT\&E the infrasound prototype was evaluated against requirements listed in the System Requirements Document (SRD) based on the Conference on Disarmament/Ad Hoc Committee on a Nuclear Test Ban/Working Papers 224 and 283 and the Preparatory Commission specifications as defined in CTBT/PC/II/1/Add.2, Appendix X, Table 5. The evaluation was conducted during a two-day period, August 6-7, 1997. The System Test Plan (STP) defined the plan and methods to test the infrasound prototype. Specific tests that were performed are detailed in the Test Procedures (TP).

The infrasound sensors passed all of the requirements with the exception of dynamic range. Three of the four sensors passed the dynamic range requirement of $80 \mathrm{~dB}$. The dynamic range of the sensor that failed was $76.9 \mathrm{~dB}$ (Table 1) and the sensor self noise (Figure 3) was approximately $25 \mathrm{~dB}$ higher than the quietest sensor. We are working with the vendor to improve quality control during microbarograph manufacturing. The quietest sensors also passed current PrepCom Working Group B specifications.

The Teledyne Brown/Geotech Instruments DR-24 digitizer met or exceeded all of our requirements. The infrasound prototype digitizer includes a GPS receiver, authentication software, step calibration software, and DC/DC power conditioning.

For a complete description of the equipment included in the infrasound prototype refer to the Hardware Design Document for the Infrasound Prototype (HDD). The HDD describes the infrasound prototype in detail using block diagrams and photographs of the prototype as currently installed at LANL. The HDD also includes a complete parts list for the prototype. 


\section{Introduction}

\subsection{Purpose}

The purpose of Development Test and Evaluation (DT\&E) is to evaluate the performance of the infrasound prototype against the requirements as specified in the System Requirements Document (SRD).

\subsection{Scope}

The Test Report (TR) (this document) describes the results of the DT\&E of the Infrasound Prototype. DT\&E was conducted during a two-day period, August 6-7, 1997. The System Test Plan (STP) defines the plan and methods to evaluate the infrasound prototype. The specific tests that were performed are detailed in the Test Procedures (TP).

\subsection{Reference Documents}

Program Plan

SRD

STP

TP

HDD
Program Plan for the Infrasound Prototype Development, SNL-CTBT-0001, dated August 12, 1996

System Requirements Document for the Infrasound Prototype, SNL-CTBT-0002, dated August 16, 1996

System Test Plan for the Infrasound Prototype, SNL-CTBT-0006, dated August 18, 1997

Test Procedures for the Infrasound Prototype, SNL-CTBT-0007, dated August 18, 1997

Hardware Design Document for the Infrasound Prototype, dated November 1997 


\section{Test Configuration}

Figure 1 shows the infrasound prototype DT\&E test configuration as installed near Los Alamos National Laboratory (LANL). Figure 1 divides the infrasound prototype into the Infrasound Array, Intrasite Communications, and the Receiving (Host) Station. The prototype spacing is approximately $1 \mathrm{~km}$ on a side. A detailed block diagram of the components that make up the infrasound prototype is shown in Figure 2.

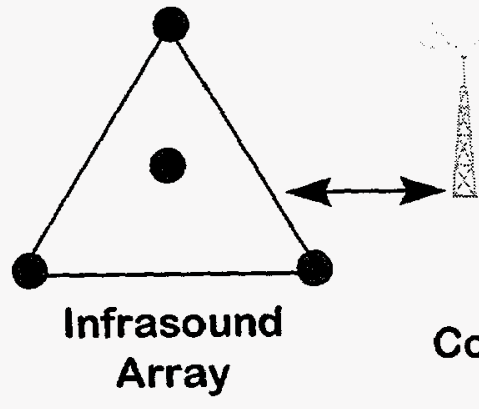

\section{Intrasite Communications}

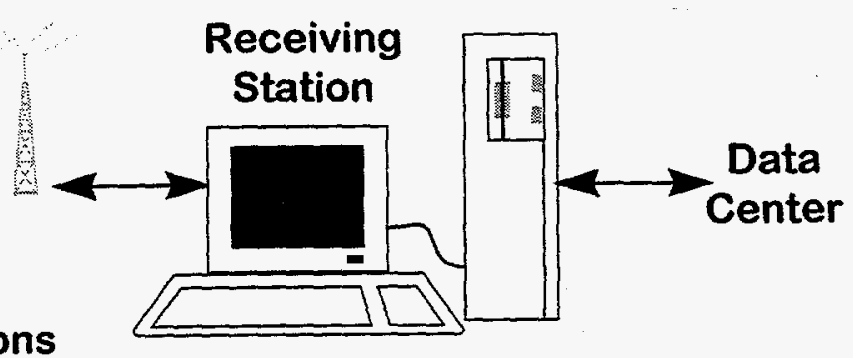

Figure 1. Block Diagram Of The INFRAsound Prototype.
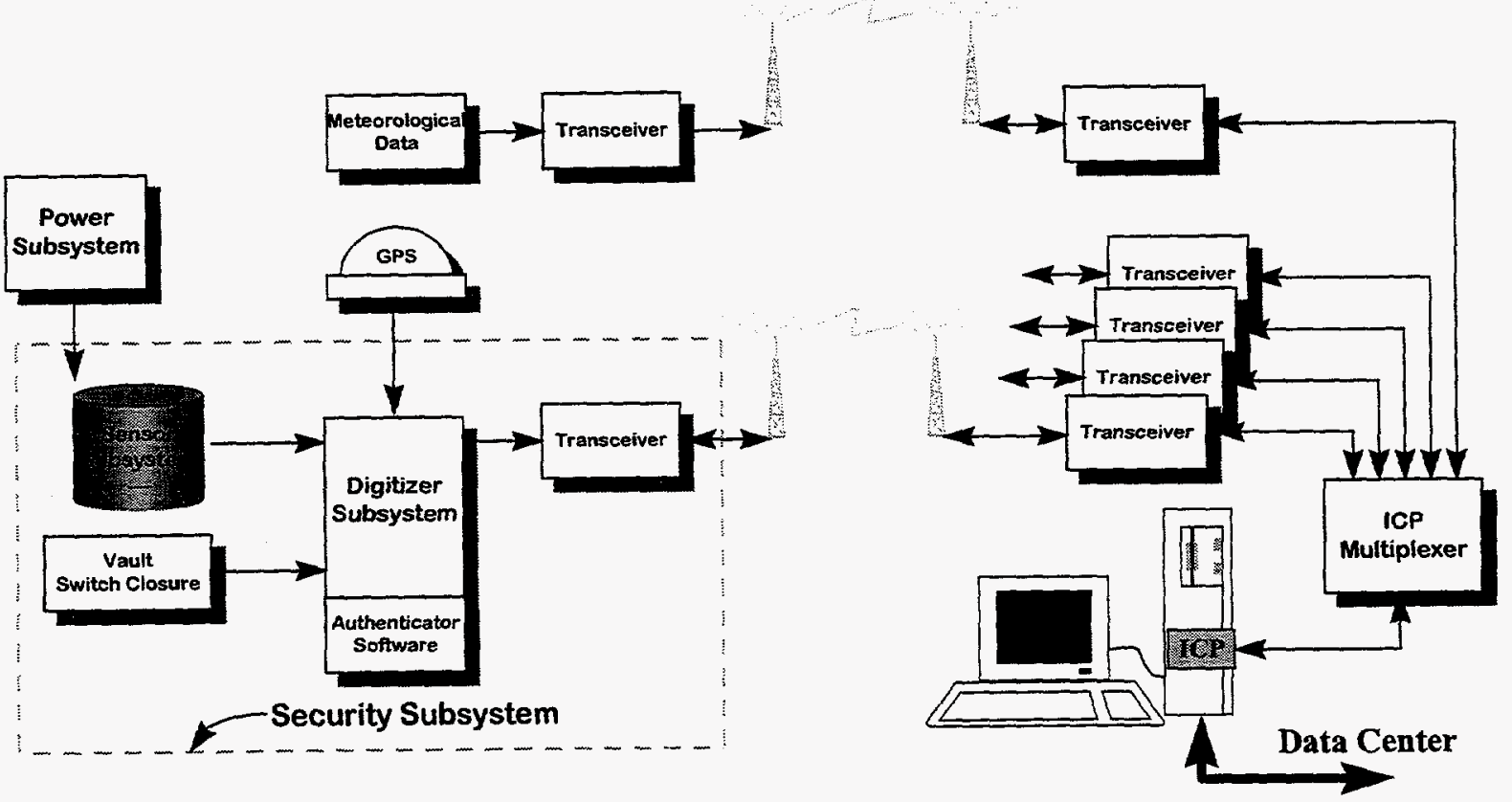

Figure 2. Detalled Block Diagram OF The Infrasound Prototype.

Each array element acquires infrasound and State-of-Health $(\mathrm{SOH})$ information, formats the data, and interfaces the data to the intrasite communications for transmission to the receiving station. A system (at the center element) acquires meteorological information (outside temperature, wind speed, and wind direction) formats the data, and interfaces the data to a separate intrasite communications for transmission to the receiving station. 


\section{Test Setup}

Sandia National Laboratories (SNL) and Los Alamos National Laboratory (LANL) were the agencies responsible for evaluating the infrasound prototype.

\subsection{Test Managers}

Dale Breding, SNL, and Rod Whitaker, LANL, served as the Test Managers. They were responsible for DT\&E, including the test plan and procedures. The test plan and procedures identified the number and type of tests to be performed.

\subsection{Test Working Group}

The Test Working Group (TWG) provided overall guidance to the Test Managers for the test program. The TWG had representatives from SNL and LANL. The TWG:

- Approved the test plans and procedures

- Provided recommendations to the Test Manager on testing issues

- Approved the test report

\subsection{Task Groups}

Task groups were organized around functionality to be tested. Each group was responsible for executing a unique set of Test Procedures and recording corresponding test results. Once the task group completed a test procedure, they summarized their findings. At the end of each day, each task group summarized their results. For DT\&E, three task groups were formed: Pretest, Inspection/Analysis, and Demonstration.

Test Procedures served as the basic set of required procedures. The task groups modified or extended the procedures as necessary to ensure that testing was adequate. For example, a test may have begun by observing results on the workstation display, but may have been extended to checking documentation or adding to the test data set.

At the end of testing, each task group reported its overall findings and conclusions to the entire group. Recommendations and issues were recorded as input to the Test Report. 


\section{Summary Results}

This section lists key requirements and summary results for each component/system in the infrasound prototype.

\subsection{Infrasound Array Element}

Each array element includes a sensor with noise reduction hoses, digitizer, data surety features, power system, and SOH data. In addition, the center array element includes meteorological data.

\subsubsection{Sensor - Microbaragraph}

The microbaragraph ${ }^{1}$ is a 10 " diameter Chaparral Physics model \# 4.11. The vendor repackaged the sensor to accommodate the infrasound prototype data surety features.

\section{Key Requirements}

- Frequency response - flat from 0.02 to $5.0 \mathrm{~Hz}$

- Resolution - $0.01 \mathrm{~Pa} @ 1.0 \mathrm{~Hz}$

- Dynamic Range - $\geq 80 \mathrm{~dB}$

- Noise reduction hoses - required

- Manual calibration capability w/known acoustic source such as a piston phone required

- Step signal calibration of sensor \& digitizer - required

\section{Results}

The infrasound sensors passed all of the above requirements with the exception of dynamic range. Three of the four sensors passed the dynamic range (Table 1) requirement. The sensor that failed had a self noise (Table 1 and Figure 3) that was approximately $25 \mathrm{~dB}$ higher than the quietest sensor. We are working with the vendor to improve quality control during microbarograph manufacturing. The quietest sensors also passed current PrepCom Working Group B specifications ${ }^{2}$.

Table 1. Dynamic Range and Sensor Noise.

\begin{tabular}{|c|c|c|}
\hline $\begin{array}{c}\text { Sensor } \\
\text { Number }\end{array}$ & $\begin{array}{c}\text { Sensor RMS full-scale } \\
\text { Sensor RMS Noise }\end{array}$ & $\begin{array}{c}\text { Dynamic } \\
\text { Range }\end{array}$ \\
\hline \hline 49 & $7.07 \mathrm{~V} / 76.8 \mu \mathrm{V}$ & $99.2 \mathrm{~dB}$ \\
\hline 50 & $7.07 \mathrm{~V} / 51.6 \mu \mathrm{V}$ & $102.7 \mathrm{~dB}$ \\
\hline 51 & $7.07 \mathrm{~V} / 209 \mu \mathrm{V}$ & $90.6 \mathrm{~dB}$ \\
\hline 55 & $7.07 \mathrm{~V} / 1001 \mu \mathrm{V}$ & $76.9 \mathrm{~dB}$ \\
\hline
\end{tabular}

\footnotetext{
${ }^{1}$ For the sensor transfer function, see Appendix A, Memorandum, Tim McDonald to Dale Breding, dated 2 October 1997, "Infrasound Sensor/Electronics Transfer Function".

2 See Appendix A, Memorandum, Tim McDonald to Dale Breding, dated 4 September 1997, "Infrasound Sensor Specification Interpretation (revisited)".
} 


\section{Chaparral 4.11 Infrasound Sensor Resolution}

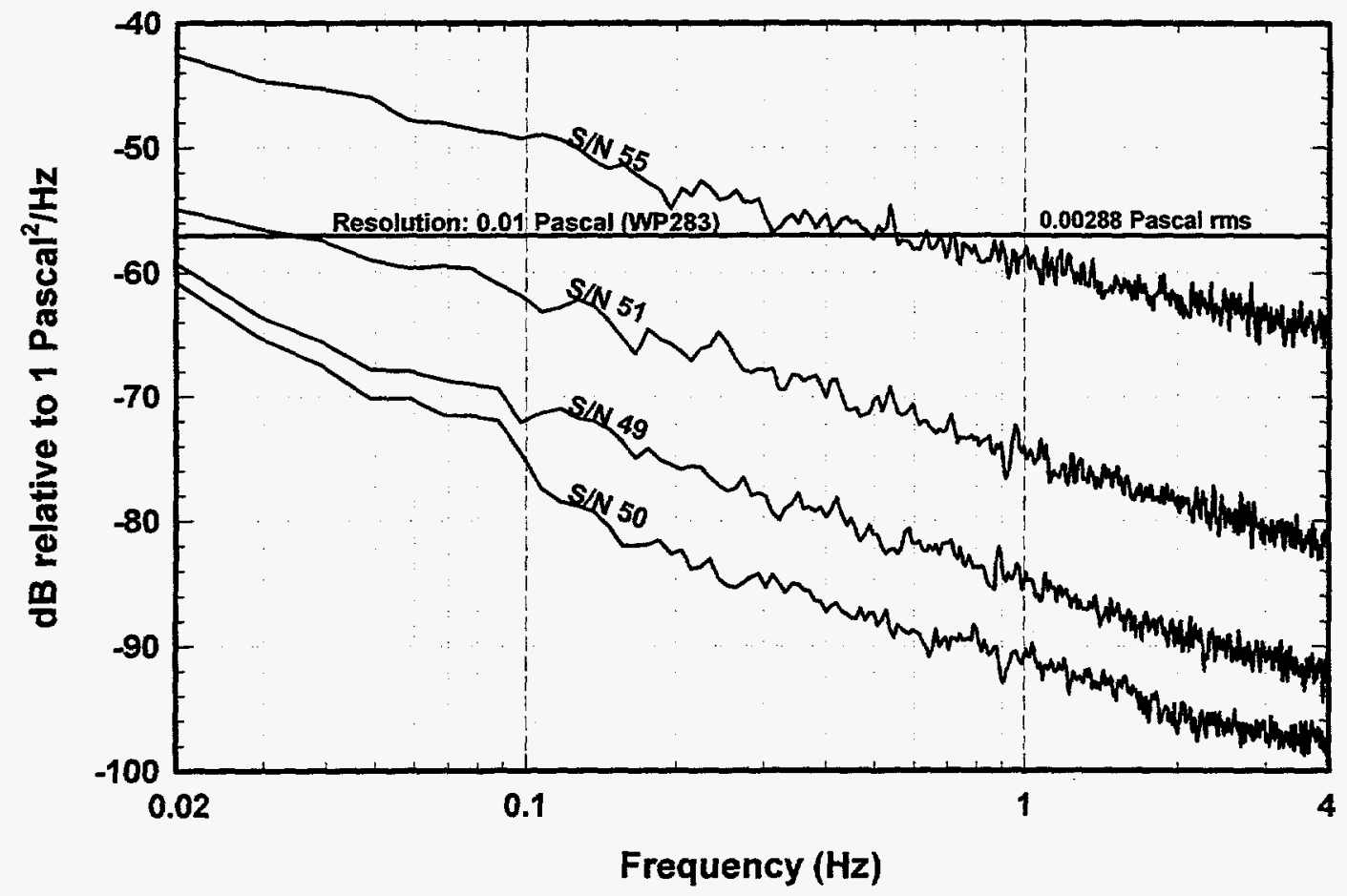

Figure 3. Measured Sensor Self Noise and Specified Resolution at $1 \mathrm{~Hz}$.

\subsubsection{Digitizer}

Array element data are acquired by a digitizer ${ }^{3}$ that includes a GPS receiver, authentication software, step calibration software, and DC/DC power conditioning. The digitizer is a Teledyne Brown/Geotech Instruments model DR-24.

\section{Key Requirements}

- Digitizer resolution - at least 20 bits

- Sample rate - 10 samples per second (sps)

- Passband $-3 \mathrm{~dB}$ points of less than $0.02 \mathrm{~Hz}$ and greater than $3.75 \mathrm{~Hz}$ (for $10 \mathrm{sps}$ )

- Nyquist frequency attenuation - at least $80 \mathrm{~dB}$

- Sensitivity - better than $2^{19}$ counts per $+/-10$ volts $+/-1.0 \%$

- Digitizer synchronization - Global Positioning System (GPS) with an accuracy better than $1.0 \mathrm{msec}$

\footnotetext{
${ }^{3}$ For the digitizer transfer function, see Appendix A, Memorandum, Tim McDonald to Dale Breding, dated 4 September 1997, "DR-24 Digitizer Response".
} 


\section{Results}

The digitizer met or exceeded all of the above requirements. This section details the test results for the four most significant requirements:

1. Digitize signal with at least a 20-bit resolution analog-to-digital converter (ADC).

Resolution implies resolving a very small signal in the presence of a very large signal. For 20-bit resolution the ratio of the large to small signal should be $120 \mathrm{~dB}$. Test results demonstrated at least 20-bit resolution for all digitizers.

A typical spectral power density is shown in Figure 4. The $1.02 \mathrm{~Hz}$ input signal is 120 $\mathrm{dB}$ larger than the small $3.41 \mathrm{~Hz}$ input signal. Note that the small signal $(3.41 \mathrm{~Hz})$ can be resolved by at least $20 \mathrm{~dB}$ indicating resolution is better than $120 \mathrm{~dB}$.

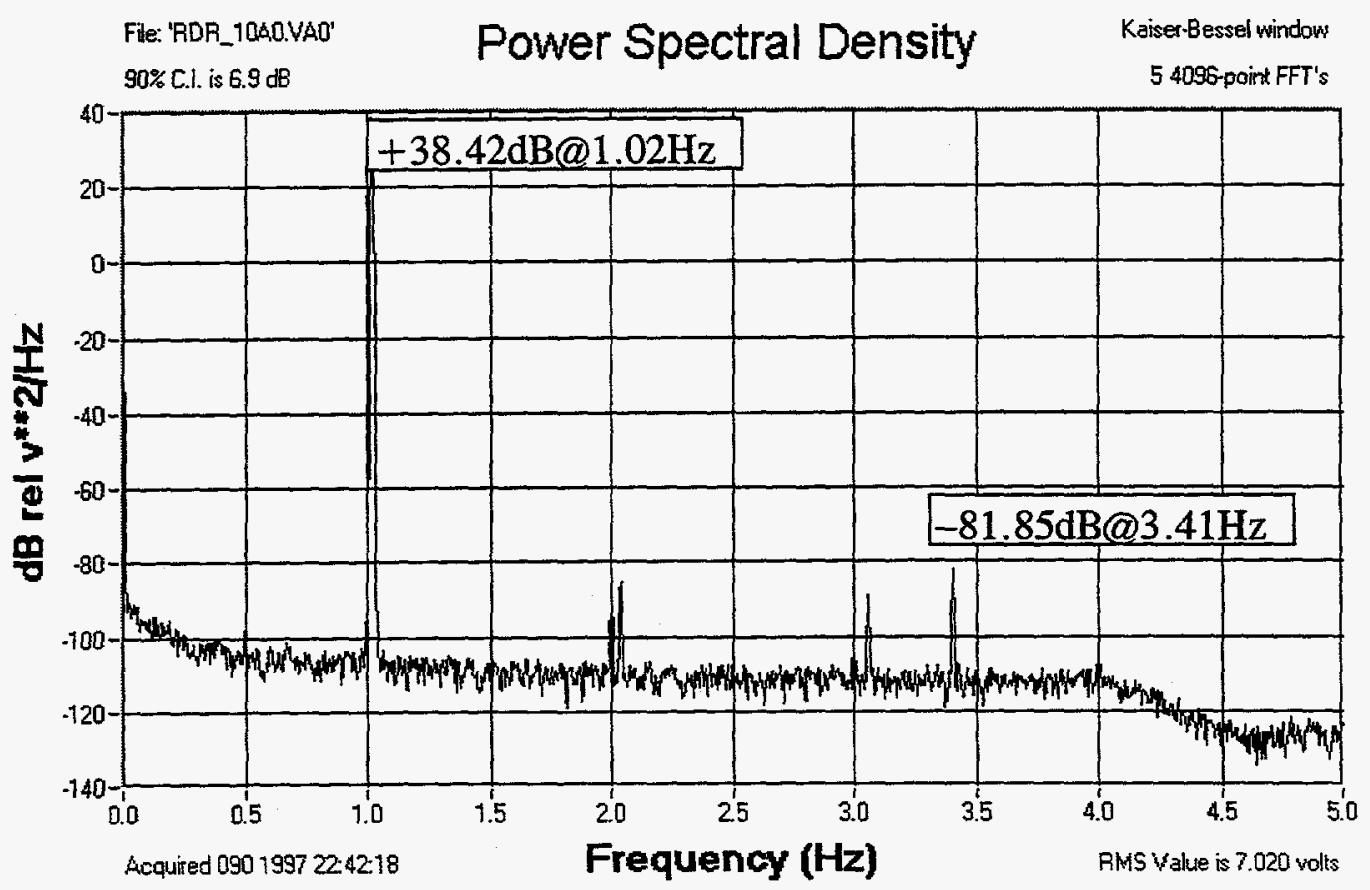

Figure 4. Resolution from a Power Spectral Density Plot. 
2. The digitizer passband ( $3 \mathrm{~dB}$ points) should be at least $0.02 \mathrm{~Hz}$ to $3.75 \mathrm{~Hz}$ at $10 \mathrm{sps}$.

3. The digitizer attenuation at the $5-\mathrm{Hz}$ Nyquist frequency should be at least $80 \mathrm{~dB}$.

Testing of passband and attenuation was accomplished by inserting a broadband signal into the digitizer and analyzing the output via a power spectral density plot. Typical power spectral density results are shown in Figure 5. NOTE: The upper bandwidth roll-off is above $3.75 \mathrm{~Hz}$, and the attenuation at the Nyquist frequency is greater than $80 \mathrm{~dB}(-115 \mathrm{~dB} @ 5.0 \mathrm{~Hz}$ Nyquist).

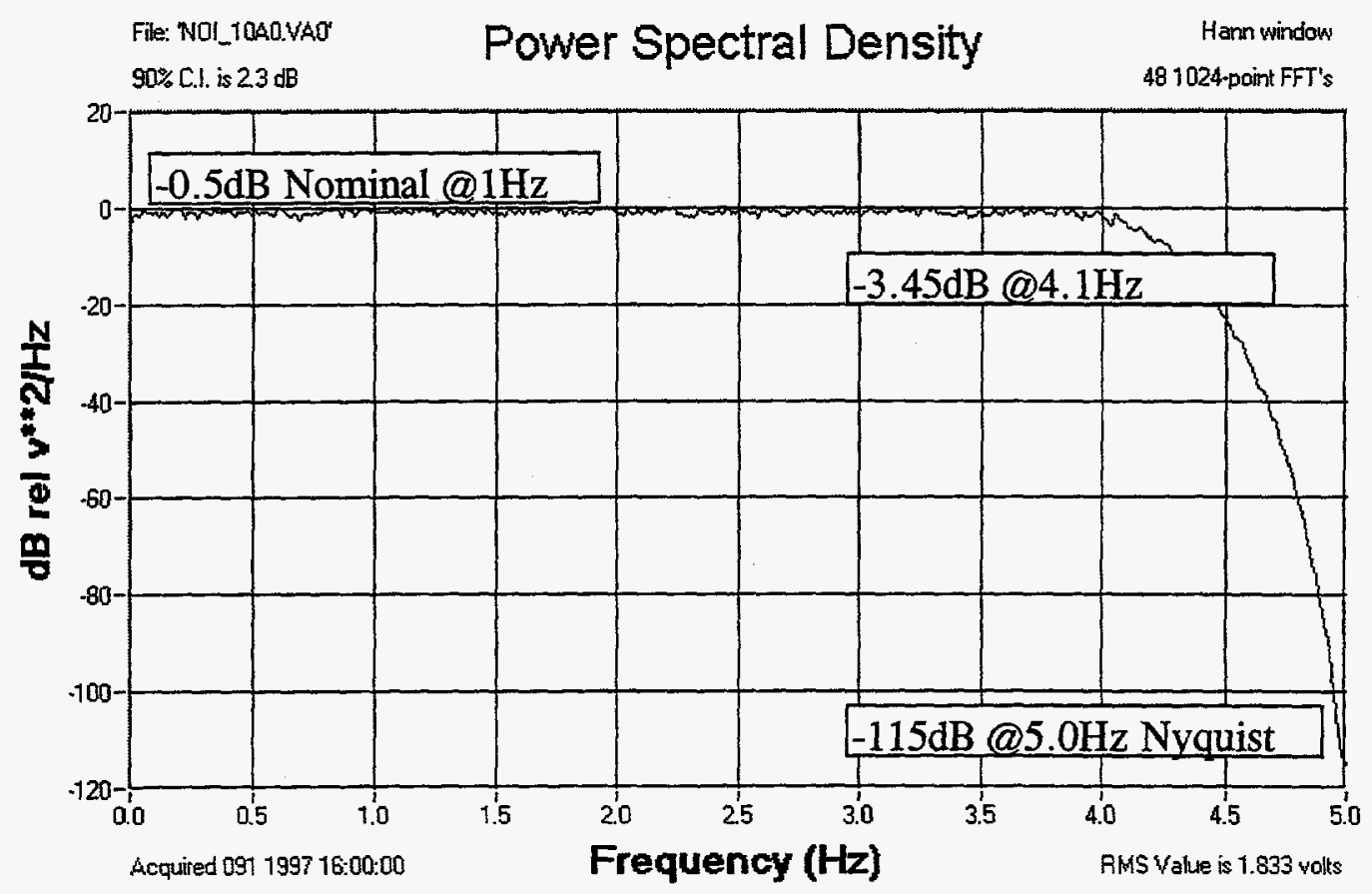

Figure 5. Passband and Attenuation at the Nyquist Frequency.

4. Digitize signal with a sensitivity of at least $2^{19}$ counts per $+/-10$ volts $+/-1.0 \%$.

A DC voltage standard was used as the digitizer input. The digitizer output was compared with the DC voltage standard input. Results (Table 3) indicate that the errors were all less than $1.0 \%$.

TABLE 2. SENSITIVITY ERRORS OF THE FOUR INFRASOUND DR-24 DIGITIZERS.

\begin{tabular}{|l|l|l|l|}
\hline $0.029 \%$ & $0.389 \%$ & $0.380 \%$ & $0.866 \%$ \\
\hline
\end{tabular}




\subsubsection{Data Surety Features}

Data surety is provided by both data authentication and tamper protection. Data authentication allows the infrasound data to be transmitted "in the clear", but with a high degree of confidence that the data received are the data that were transmitted. Data authentication for the infrasound prototype is performed in a software module 4 in the digitizer.

Tamper protection is provided by housing the array element hardware (sensor, digitizer, authenticator, etc.) in a secure enclosure. The enclosure is buried in the ground and could include both active and passive tamper protection.

\section{Key Requirements}

- Data authentication - required at one element of the infrasound array

- Data authentication - capability required at all array elements

- Data authentication - public key standard required

- Active tamper detection - required at each element

- Passive tamper detection - capability required at all array elements

\section{Results}

Five frames of infrasound data were signed and transferred, in the alpha format, to SNL and the signatures were successfully authenticated for all five frames. SNL furnished the software implementation of the Digital Signature Algorithm used for data authentication in the prototype system. The prototype is capable of authentication at all elements to meet the PrepCom Working Group B specifications.

An active tamper detection device (switch closure) was installed on each buried enclosure. Each enclosure is capable of including a passive tamper detection device, such as a seal.

\subsubsection{Array Element Power System}

Primary power is provided to each array element by a photovoltaic solar cell array with integral batteries to provide backup power at night, on cloudy days, or in case of primary power failure.

\section{Key Requirements}

- Primary power - a solar array required at each array element

- Battery backup - required to operate the infrasound array for a minimum of 72hours

\section{Results}

The array element photovoltaic solar cell array performed flawlessly during DT\&E. The 72-hour backup requirement was tested by comparing the measured array element power

\footnotetext{
${ }^{4}$ PrepCom Working Group B recommends performing authentication in a tamper protected module that is separate from the digitizer.
} 
drain for 72 hours and power rating of the batteries. Additional testing on these requirements will be performed during the one-year operational test period.

\subsubsection{Meteorological Station, State of Health}

Meteorological data (outside temperature, wind speed, and wind direction) were collected at the center element. These data were transmitted to the receiving station via its own intrasite communications. The meteorological intrasite communications hardware is identical to the array element communications hardware. SOH data (DC power voltage, internal temperature and tamper detection switch closure) were collected at each array element (internal to the DR-24) and were transmitted to the receiving station with the infrasound data.

\section{Key Requirements}

- Meteorological data - required at the center elements: outside temperature, wind speed, and wind direction

- SOH data - required at the each array element: DC power voltage, internal temperature and tamper detection switch closure

\section{Results}

The prototype satisfactorily collected SOH data (DC power voltage, internal temperature and tamper detection switch closure) at each element and successfully collected meteorological data (outside temperature, wind speed, and wind direction) at the center element.

\subsection{Intrasite Communications}

FreeWave spread spectrum transceivers (model DGR-1155) were utilized to transmit data from each of the array elements to the receiving station. Five transceiver pairs were installed on the prototype, four for the infrasound/SOH data and one for the meteorological data. Power output is adjustable up to one watt, and the transceivers are capable of transmitting to a range of 20 miles.

\section{Key Requirements}

- Data transmission - transmission of the following digital data required from each element to the multiplexer: one channel of infrasonic data, three channels of SOH data

- Data transmission - transmission of three channels of meteorological data from the center element required

- Modems - spread spectrum RF modems required

- Error detection - retransmission protocols, such as Cyclical Redundancy Check $(\mathrm{CRC})$, required for all data transmitted from the sensor site to the multiplexer

- Meteorological data transmission - separate transmitter required

\footnotetext{
${ }^{5}$ Model DGR-115H is recommended for future infrasound systems as the aluminum housing should provide additional RFI protection.
} 


\section{Results}

The intrasite communications, utilizing the spread spectrum transceivers, had excellent performance during DT\&E. Error detection/retransmission was designed into the spread spectrum transceiver. An additional layer of error detection/retransmission was built into the DR-24 digitizers.

\subsection{Receiving Station}

\subsubsection{Multiplexer}

The multiplexer combines the four serial infrasound data channels and one channel of meteorological data and then interfaces the combined data stream to the NT workstation.

\section{Key Requirements}

- Data reception - receive 1 channel of infrasound data and 3 channels of SOH data from each of 4 array elements and 3 channels of meteorological data from the center element

- Data output - output 4 channels of infrasound data, 3 channels of meteorological and 3 channels of $\mathrm{SOH}$ data from each array element

\section{Results}

The infrasound prototype multiplexer successfully received and transferred all infrasound, $\mathrm{SOH}$, and meteorological data to the NT workstation during DT\&E.

A single multiplexer is expandable to receive data from any seismic or infrasound array under consideration for the Internal Monitoring System.

\subsubsection{NT Workstation}

The NT workstation provides the operator with the capability to monitor the array element infrasound data, $\mathrm{SOH}$, and meteorological information. The infrasound prototype workstation utilizes a Pentium CPU, with a $133 \mathrm{MHz}$ clock rate, running Microsoft Windows NT. The NT workstation receives data from the multiplexer, stores it locally in CSS 3.0, and displays all array element data (infrasound, $\mathrm{SOH}$, and meteorological). In addition, the workstation can configure most digitizer parameters. A portable computer connection at the digitizer is required to change a few digitizer parameters.

\section{Key Requirements}

- Infrasound data displays - display four channels of infrasound data on a scrolling or buffered snapshot display

- SOH data displays - display all SOH data in a tabular format and a buffered snapshot display

- Data Storage - store all infrasound data in the CSS format for 1 month 


\section{Results}

The NT workstation operation and displays exceeded our expectations. User-friendly pulldown menus were provided to display the four real-time infrasound data channels or to display the data stored in the CSS 3.0 format. The operator could control the display amplitude and time scale for the stored infrasound data. These features provided excellent control for the operator to monitor the collection of the infrasound data.

The primary display for the $\mathrm{SOH}$ and meteorological data was in tabular form. The tabular data were converted to engineering units (VDC, $\mathrm{mph}$, etc.) for ease of interpretation. The tabular display was very good for assessing the current operation of the prototype. $\mathrm{SOH}$ and meteorological data stored on disk could be displayed to view longer-term trends, such as battery voltage change when the primary power system was not producing power (on cloudy days, or in case of primary power failure).

\subsubsection{Intersite (Prototype-to-NDC) Communications.}

Intersite communication, from the prototype to the US National Data Center (NDC), is provided by a standard computer-to-computer protocol (TCP/IP). This well understood, mature protocol provides the necessary functionality to reliably communicate the infrasound, SOH, and meteorological data to the US NDC.

\section{Key Requirements}

- Alpha protocol - required for all infrasound and SOH data sent to the US NDC

- Error detection - retransmission protocol, such as CRC, required for all data sent to the US NDC

- Data transmission to the US NDC - four channels of infrasonic data, three channels of SOH data from each element, and three channels of meteorological data from the center element required

\section{Results}

Infrasound data was successfully transmitted in the alpha protocol to the US NDC. US NDC personnel gave some statistics indicating the transmission was very good. For several days data transmission was better than $99 \%$, missing only one to three thirtysecond data blocks.

$\mathrm{SOH}$ and meteorological data were also sent to the US NDC. With the exception of the "vault door open bit", SOH and meteorological data transmission is not well defined in the alpha protocol format (see recommendations). As a result, the US NDC could not confirm successful $\mathrm{SOH}$ and meteorological data transmission. 


\section{Recommendations}

While the infrasound prototype met or exceeded most key requirements, a few recommendations for future system procurements are appropriate.

- SENSOR/DIGITIZER IMPEDANCE MISMATCH - Add an impedance-matchingvoltage-follower operational amplifier in the digitizer to raise the input impedance from $\sim 10 \mathrm{~K} \Omega$ to $\sim 10 \mathrm{M} \Omega$

DISCUSSION: Subsequent to DT\&E, the development team discovered an impedance mismatch between the sensor and the digitizer. The sensor output impedance is $~ 100$ $\mathrm{K} \Omega$. The DR-24 digitizer input impedance is $\sim 10 \mathrm{~K} \Omega$. An impedance-matchingvoltage-follower operational amplifier in the digitizer should solve the impedance mismatch at only a small increase in the digitizer noise floor.

- AUTHENTICATION - Perform authentication in a tamper protected module external to the digitizer

DISCUSSSION: PrepCom Working Group B has recommended performing authentication in a tamper protected module external from the digitizer for new systems. NOTE - The prototype could be easily modified to meet the PrepCom Working Group B recommendation.

- SOH AND METEOROLOGICAL DATA - PrepCom should identify which SOH and meteorological data are required, the sample rate, and where the information should reside in the data frame format

DISCUSSION: Currently the alpha protocol only loosely defines the location of the SOH and meteorological data by stating: "The Data Frame consists of a header and Channel Sub-Frames.... The header contains size and time information and possibly weather or other SOH data, whereas the Channel Sub-Frame contains the authentication as well as the actual data."

NOTE: Should the PrepCom decide that the meteorological data should be sampled once per second, the data frame header may not be adequate to transmit this data.

- INPUT VOLTAGE - Operate the infrasound system on 12 VDC DISCUSSION: The prototype was operated on $24 \mathrm{VDC}$ to accommodate the sensor. As all other components operated on $12 \mathrm{VDC}$, a DC-DC converter had to be provided for those components. For 12 VDC operation, a DC-DC converter will still be required for the sensor unless the vendor provides a sensor that operates on 12 VDC.

- STATION SOH DISPLAYS - Provide similar options for displaying the stored

$\mathrm{SOH}$ and meteorological data as are provided for the infrasound data

DISCUSSION: The operator can control the display amplitude and time scale for the stored infrasound data. These features provided excellent control for the operator to monitor the collection of the infrasound data. It would be useful to have the same options for the $\mathrm{SOH}$ and meteorological data. 
- DIGITIZER OUTPUT BUFFER - Add a short $(<5 \mathrm{sec}$.) buffer in the digitizer output to facilitate the error detection/retransmission which is built into the DR-24 digitizers

DISCUSSION: While the DR-24 digitizer has an error detection/retransmission protocol built into it, the prototype digitizer does not have a storage buffer to accommodate short data transmission losses. Since error detection/retransmission protocols are designed to correct for bit errors, only a short buffer should be required in the digitizer.

- GPS LOCATION DATA - PrepCom should facilitate utilizing the GPS location information (latitude, longitude, and elevation)

DISCUSSION: GPS location information (latitude, longitude, and elevation) are routinely collected by digitizers that contain GPS receivers. By averaging these data, very accurate station locations for each element could be obtained. Therefore, PrepCom should facilitate utilizing the GPS location information (latitude, longitude, and elevation). 


\section{Appendix A - Related Memoranda}

MEMorandum - Tim MCDONALD to DALE BREDING, DATEd 4 SePTEMBER 1997

Infrasound Sensor Specifications Interpretation (revisited)

MEMoraNDUM - TIM MCDONALD TO DALE BREDING, DATEd 4 SEPTEMBER 1997 18

DR-24 Digitizer Response

MEMORANDUM - TIM MCDONALD TO DALE BREDING, DATEd 2 OCTOBER 1997 .30

Infrasound Sensor/Electronics Transfer Function 


$\begin{array}{ll}\text { Date: } & \text { 4 September 1997 } \\ \text { To: } & \begin{array}{l}\text { Dale Breding, SNL 5704 } \\ \text { Tim McDonald (API), SNL 5736 }\end{array} \\ \text { Subject: } & \begin{array}{l}\text { Infrasound Sensor Specification Interpretation } \\ \text { (revisited) }\end{array}\end{array}$

Note: This is a revision of my 1 May 97 memo - the sensor self-noise line on the graph on the next page is the result of a more recent measurement. The curve for the lowest noise sensor ( $/ \mathrm{n} 50)$ is shown. Also, the dynamic range specification interpretation has been changed to $80 \mathrm{~dB}$ below $a-10$ to +10 volt sine rather than a uniform random variate; this modification resulted in raising the Dynamic Range Floor by approximately $1.8 \mathrm{~dB}$.

I understand there were several comments, suggestions, and questions concerning my 24 April memo to you about the interpretations I made of the infrasound sensor specifications. Some further explanation and clarification is in order. While emphasizing that other interpretations of the specifications are possible, I believe those I have followed are fairly standard and make sense.

One suggestion I agree with and have incorporated in this note is that pressure units as opposed to voltage units should be used in the specification graph. Accordingly, the $y$-axis on the graph included on the next page is in " $\mathrm{dB}$ relative to $1 \mathrm{Pascal}^{2} / \mathbf{H z}$ " instead of the original " $\mathrm{dB}$ relative to $1 \mathrm{volt}^{2} / \mathrm{Hz}$ ", and the sensor sensitivity of $40 \mathrm{mvolts} / \mu \mathrm{bar}$ (assumed flat across the bandwidth) is used to convert the sensor self-noise power spectral density and the calculated dynamic range floor from volts to pressure units. This change of units should make the graph on page 2 more readable and more relevant to the sensor community.

There were questions about some of the spectral levels themselves; in particular, how could the level for 0.005 Pascal rms (Acoustic Noise Limit) possibly be above the level for 0.01 Pascal (WP283 Resolution)? The answer is that the former was taken to be an rms specification while the latter was interpreted to specify the range of a uniform random variate. In order to make the labeling less disturbing, I have added the corresponding rms value to the spectral level labels where appropriate.

The interpretation of the specifications into spectral levels remains unchanged except for the units used:

\section{Resolution}

For the resolution specifications ( 1 count $\leq 0.001$ Pascal [PrepCom] or 0.01 Pascal [WP283]) I have used the argument that a resolution limit is determined by the "worst case" signal that cannot be resolved. In standard practice, this is interpreted to mean the spectrum of a uniform random variate with a range of $-\mathbf{R} / 2$ to $+\mathbf{R} / 2$ (where $\mathbf{R}$ is the resolution specification) having power distributed evenly over the bandwidth B [Stearns, 1975]:

$$
\text { Resolution Level }=10 \log _{10}\left(\frac{\mathrm{R}^{2}}{12 \times \mathrm{B}}\right) \mathrm{dB} \text { relative to } 1 \mathrm{Pascals}^{2} / \mathrm{Hz}
$$

Then, for the WP283 resolution specification of 0.01 Pascal we get

$$
\mathrm{B}=4.0 \mathrm{~Hz}-0.02 \mathrm{~Hz}=3.98 \mathrm{~Hz} \text { and }
$$




$$
\text { (Resolution Level) })_{0.01}=10 \log _{10}\left(\frac{0.01^{2}}{12 \times 3.98}\right) \mathrm{dB}=-\mathbf{5 7} \mathrm{dB} \text { relative to } 1 \mathrm{Pascal}^{2} / \mathrm{Hz} \text {. }
$$

Similarly, the PrepCom resolution specification of 0.001 Pascal becomes $-77 \mathrm{~dB}$.

\section{Sensor Noise Limit}

The PrepCom specification for sensor noise limit is $18 \mathrm{~dB}$ below the minimum acoustic noise, which, in turn, is specified at $1 \mathrm{~Hz}$ as approximately 0.005 Pascals. Usually noise is expressed as an rms value; using this interpretation, and again distributing the power evenly over the bandwidth B, the level is calculated

$$
\text { Acoustic Noise Limit }=10 \log _{10}\left(\frac{(0.005 \mathrm{~Pa})^{2}}{3.98 \mathrm{~Hz}}\right)=\mathbf{- 5 2} \mathrm{dB} \text { relative to } 1 \mathrm{Pascal}^{2} / \mathrm{Hz}
$$

The sensor noise limit is $18 \mathrm{~dB}$ below this value, or $-\mathbf{7 0} \mathrm{dB}$.

\section{Dynamic Range}

Finally, the floor for the $80 \mathrm{~dB}$ dynamic range specification is obtained by subtracting $80 \mathrm{~dB}$ from the level obtained for $a-10$ to +10 volt (sensor clip level) sine wave (changed from original memo); this is calculated as $(11-80)$, or $-69 \mathrm{~dB}$ relative to 1 volt ${ }^{2} / \mathrm{Hz}$, which, for a sensor sensitivity of 40 mvolts/ $\mu$ bar across the bandwidth, becomes $-61 \mathrm{~dB}$ relative to $1 \mathrm{Pascal}^{2} / \mathrm{Hz}$.

Note that all of these spectral levels are independent of the chosen digitizer, its sample rate or quantization level. Let me know if there are any questions or comments.

\section{Reference:}

Stearns, Samuel D., Digital Signal Analysis, 1975, Hayden, pp. 44-45, 226-227.

\section{Infrasound Sensor Specifications}

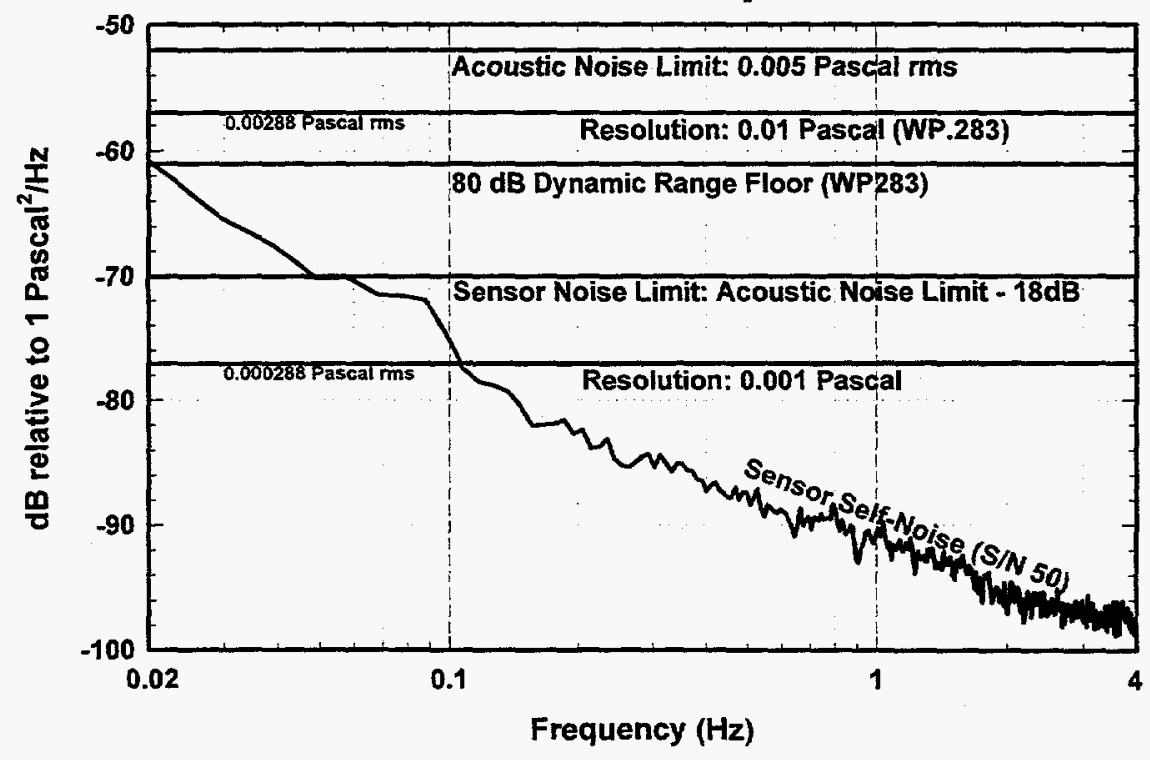


MEMORANDUM

Date:

4 September 1997

To:

Dale Breding, SNL 5704

From:

Tim McDonald (API), SNL 5736

Subject:

DR-24 Digitizer Response

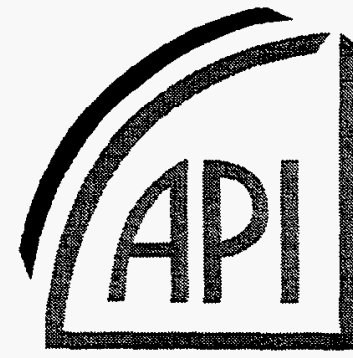

SCIENTIFIC \& TECHNICAL CONSULTANTS

An effort to define the response of the DR-24 infrasound data acquisition system digitizer has been conducted and verifies the results published in the chip set manufacturer's product documentation [1-3]. In addition, calculated step response time sequences based on a model of the Crystal Semiconductor CS5421 Delta-Sigma Modulator/CS5322 Digital Filter combination show remarkable agreement with measured step response sequences obtained from the data acquisition system.

\section{Summary}

The nature of the design of this digitizer makes its response difficult to describe in traditional terms, unless the modular operation of the system is taken as the basis of the description. The result (as you will see) is somewhat involved, and our thinking is that a simpler approximation to the digitizer response would be much more useful. Based on the calculated impulse responses of the theoretical model of the digitizer, a much simpler, normalized FIR approximation to the ensemble digitizer response was developed. Table 1 below lists the coefficients of this FIR filter, and a comparison plot of the theoretical ensemble power gain (at 10 samples/second) with the response of this approximation filter is given near the end of this memorandum in Figure 12. The transfer function of this normalized FIR filter was obtained using

$$
\mathrm{H}_{\mathrm{k}}(j \omega)=\mathrm{c}_{0}+2 \sum_{n=1}^{24} \mathrm{c}_{n} \times \cos (n \omega \mathrm{T}),
$$

where $\mathrm{T}$ is the sampling interval of 0.1 seconds.

The system gain in the flat portion of the response curve (about 263850 counts/volt) is usually obtained via calibration since it depends on analog component values; however, the response is not complete without this multiplier.

\begin{tabular}{|c|c|c|c|c|c|}
\hline $\mathrm{c}_{24} \& \mathrm{c}_{-24}$ & -0.0002 & $c_{23} \& c_{-23}$ & -0.0001 & $\mathrm{C}_{22} \& \mathrm{C}_{-22}$ & 0.0002 \\
\hline$c_{21} \& c_{-21}$ & -0.0003 & $c_{20} \& c_{-20}$ & 0.0003 & $c_{19} \& c_{-19}$ & -0.0003 \\
\hline $\mathrm{c}_{18} \& \mathrm{c}_{-18}$ & -0.0002 & $c_{17} \& c_{-17}$ & 0.0011 & $c_{16} \& c_{-16}$ & -0.0021 \\
\hline$c_{15} \& c_{-15}$ & 0.0028 & $c_{14} \& c_{-14}$ & -0.0026 & $c_{13} \& c_{-13}$ & 0.0010 \\
\hline $\mathrm{C}_{12} \& \mathrm{C}_{-12}$ & 0.0022 & $c_{11} \& c_{-11}$ & -0.0066 & $C_{10} \& C_{-10}$ & 0.0111 \\
\hline$C_{9} \& C_{-9}$ & -0.0140 & $\mathrm{C}_{8} \& \mathrm{C}_{-8}$ & 0.0133 & $c_{7} \& c_{-7}$ & -0.0073 \\
\hline$c_{6} \& c_{-6}$ & -0.0051 & $c_{5} \& c_{-5}$ & 0.0236 & $c_{4} \& c_{-4}$ & -0.0468 \\
\hline$c_{3} \& c_{-3}$ & $\begin{array}{l}0.0728 \\
0.7645\end{array}$ & $c_{2} \& c_{-2}$ & -0.1024 & $c_{1} \& c_{-1}$ & 0.1774 \\
\hline
\end{tabular}




\section{Detailed Digitizer Response}

The digitizer transfer function involves an analog filter and three digital finite-impulseresponse (FIR) filter/sample decimation sections, the second of which may be used a selectable number of times in order to achieve different sample rates. The analog front-end filter [4] has no discernible effect at the low frequencies of interest to this effort (other than to help eliminate aliasing as a concern), and is not included in the model. The delta-sigma modulator produces a bit stream based on the integrated input signal, and this stream feeds the FIR ensemble as illustrated in Figure 1.

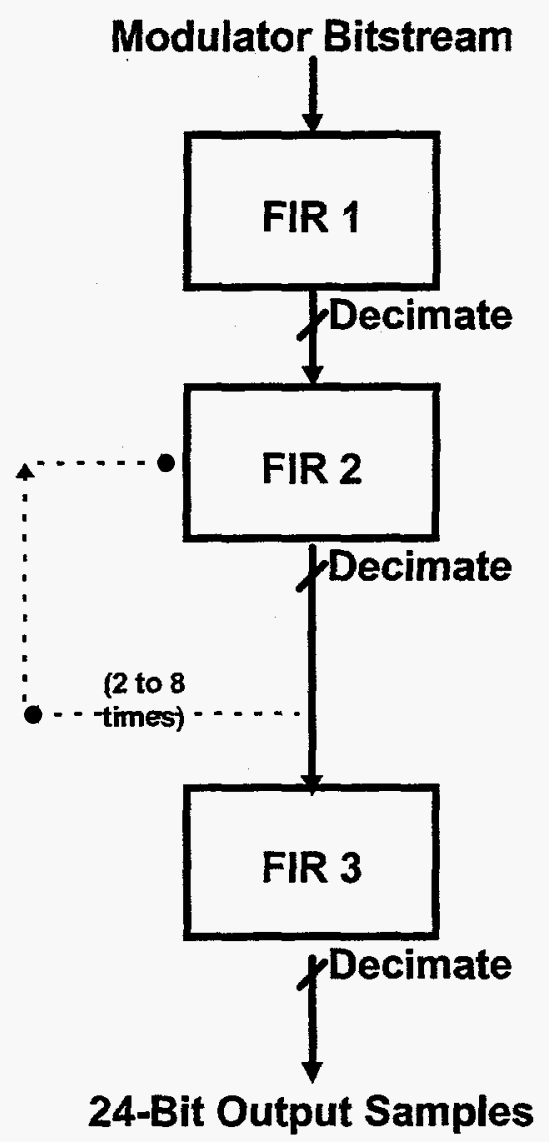

Figure 1 - CS5322 FIR Digital Filter Ensemble

The Teledyne Brown Engineering (TBE) - Geotech Instruments DR-24 uses the Crystal Semiconductor CS5321/CS5322 chip set with an input bitstream clocking of $40960 \mathrm{~Hz}$. For our 10 samples per second operation, the "FIR 2/decimate by 2 " loop is executed the maximum of 8 times. The total decimation is $2^{3} * 2^{8} * 2$, or 1 output sample in 4096 input clocks, resulting in the 10 samples per second output rate.

All three of the FIR's are symmetric, linear phase, lowpass filters. The coefficients [from reference 3] are reproduced here for convenience in Tables 2 through 4. For modeling purposes, it may be helpful to divide each of a given filter's coefficients by the sum of all its coefficients - a technique used to normalize the individual gains shown in Figures 2 
through 4 and the composite gain in Figure 5. This scaling operation results in unity gain at $\mathrm{DC}$ for the modeled segment. The system gain in the flat portion of the response curve (about 263850 counts/volt) is usually obtained via calibration since it depends on analog component values. Also, because the overall FIR delay (slope of the linear phase shift) is removed via the time-tagging of the output data samples by the digitizing system, it is convenient to renumber the coefficients by subtracting $N=$ (number of coefficients +1$) / 2$ from each of the coefficient indices in Tables 2 through 4; i.e., FIR 1 would have new coefficient indices -16 to +16 , FIR 2 indices -6 to +6 , and FIR 3 indices -50 to +50 . Note that in all cases the resulting coefficient number $-\mathbf{n}$ will equal the coefficient number $+\mathbf{n}$, and we need to retain only one of each equal pair. This renumbering scheme converts each filter to zero phase shift, agreeing with the time-tag compensation. If we designate the scaled $\mathbf{n}^{\text {th }}$ coefficient of FIR number $\mathbf{k}$ by $\mathrm{ck}_{\mathbf{n}}$ (for example, $c 2_{4}=$ 540672/33554432*), the FIR transfer functions [5] can be calculated by:

$$
\mathrm{H}_{\mathrm{k}}(j \omega)=\mathrm{ck}_{0}+2 \sum_{n=1}^{N_{\mathrm{k}}} \mathrm{ck}_{n} \times \cos (n \omega \mathrm{T})
$$

Coef \#1 \& \#33

Coef \#3 \& \#31

Coef \#5 \& \#29

Coef \#7 \& \#27

Coef \#9 \& \#25

Coef \#11 \& \#23

Coef \#13 \& \#21

Coef \#15 \& \#19

Coef \#17

Coef \#1 \& \#13

Coef \#3 \& \#11

Coef \#5 \& \#9

Coef \#7
Table 2 - FIR 1 ( 33 Coefficients)

\section{Coef \#2 \&\#32}

Coef \#4 \& \#30

10 Coef \#6 \& \#28

35 Coef \#8 \& \#26

84

161

Coef \#10 \& \#24

Coef \#12 \& \#22

246

315

344
Coef \#14 \& \#20

Coef \#16 \&\#18

\section{0}

20

56

120

204

284

336
Table 3 - FIR 2 (13 Coefficients)

8192 Coef \#2 \&\#12

540672 Coef \#4 \& \#10

4055040 Coef \#6 \& \#8

7569408
98304

1802240

6488064

\footnotetext{
* 33554432 is the sum of the FIR 2 coefficients from Table 3.
} 
Coef \#1 \& \#101

Coef \#3 \& \#99

Coef \#5 \& \#97

Coef \#7 \& \#95

Coef \#9 \& \#93

Coef \#11 \& \#91

Coef \#13 \& \#89

Coef \#15 \& \#87

Coef \#17 \& \#85

Coef\#19 \& \#83

Coef \#21 \& \#81

Coef \#23 \& \#79

Coef \#25 \& \#77

Coef \#27 \& \#75

Coef \#29 \& \#73

Coef \#31 \& \#71

Coef \#33 \& \#69

Coef \#35 \& \#67

Coef \#37 \& \#65

Coef \#39 \& \#63

Coef \#41 \& \#61

Coef \#43 \& \#59

Coef \#45 \& \#57

Coef \#47 \& \#55

Coef \#49 \& \#53

Coef \#51

\section{Table 4 - FIR 3 (101 Coefficients)}

\begin{tabular}{|c|c|c|}
\hline-26 & Coef \#2 \& \#100 & -247 \\
\hline-822 & Coef \#4 \& \#98 & -1362 \\
\hline-839 & Coef \#6 \& \#96 & 1012 \\
\hline 2197 & Coef \#8 \& \#94 & 212 \\
\hline-3443 & Coef \#10 \& \#92 & -3077 \\
\hline 3156 & Coef \#12 \& \#90 & 7168 \\
\hline 256 & Coef \#14 \& \#88 & -10709 \\
\hline-7644 & Coef \#16 \& \#86 & 10713 \\
\hline 18055 & Coef \#18 \& \#84 & -3873 \\
\hline-28007 & Coef \#20 \& \#82 & -11826 \\
\hline 31641 & Coef \#22 \& \#80 & 35194 \\
\hline-22177 & Coef \#24 \& \#78 & -60427 \\
\hline-5404 & Coef \#26 \& \#76 & 77065 \\
\hline 51056 & Coef \#28 \& \#74 & -71982 \\
\hline-106905 & Coef \#30 \& \#72 & 33416 \\
\hline 156296 & Coef \#32 \& \#70 & 43678 \\
\hline-175718 & Coef \#34 \& \#68 & -152409 \\
\hline 139856 & Coef \#36 \& \#66 & 270573 \\
\hline-29083 & Coef \#38 \& \#64 & -360427 \\
\hline-162173 & Coef \#40 \& \#62 & 371807 \\
\hline 417807 & Coef \#42 \& \#60 & -246840 \\
\hline-693181 & Coef \#44 \& \#58 & -78388 \\
\hline 902497 & Coef \#46 \& \#56 & 685231 \\
\hline-865217 & Coef \#48 \& \#54 & -1713558 \\
\hline $\begin{array}{r}-262 \\
4950471\end{array}$ & Coef \#50 \& \#52 & 3276208 \\
\hline
\end{tabular}

The individual FIR 1 through 3 transfer functions are shown in Figures 2 through 4; we need only plot the normalized power gain since the phase shift is zero. The frequency $(x)$ axis label is $\omega \mathrm{T}$, where $\omega$ is the angular frequency and $\mathrm{T}$ is the reciprocal of the input clock rate (before decimation).

The composite or ensemble response is shown in Figures 5 through 7 for the 10 samples per second case (recall that FIR 2 is executed a variable number of times, depending on the output sample rate selection). These composite response plots agree completely with the specifications and plots in the Crystal documents (see [2] in particular). 
FIR 1

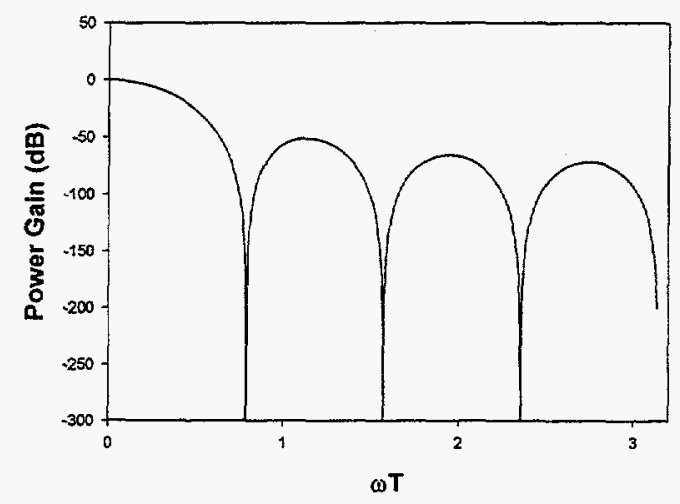

Figure 2 - Stage 1 Transfer Function

FIR 2

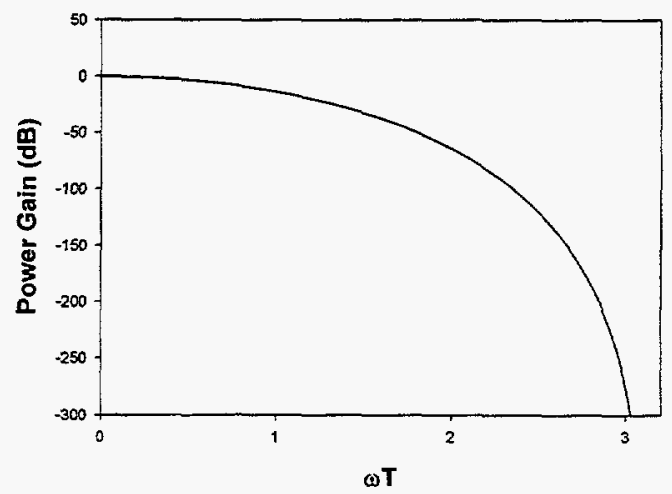

Figure 3 - Stage 2 Transfer Function

FIR 3

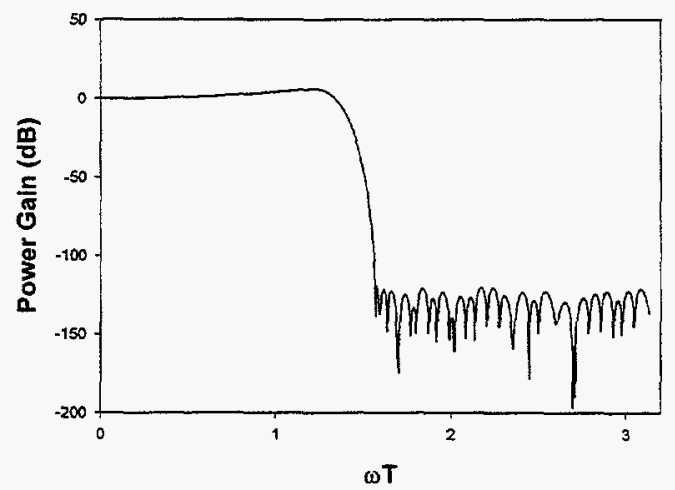

Figure 4 - Stage 3 Transfer Function 


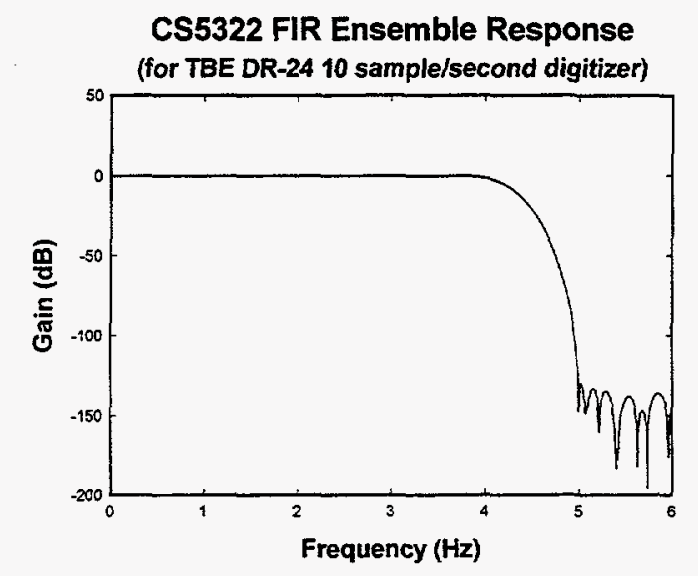

Figure 5 - Ensemble Transfer Function

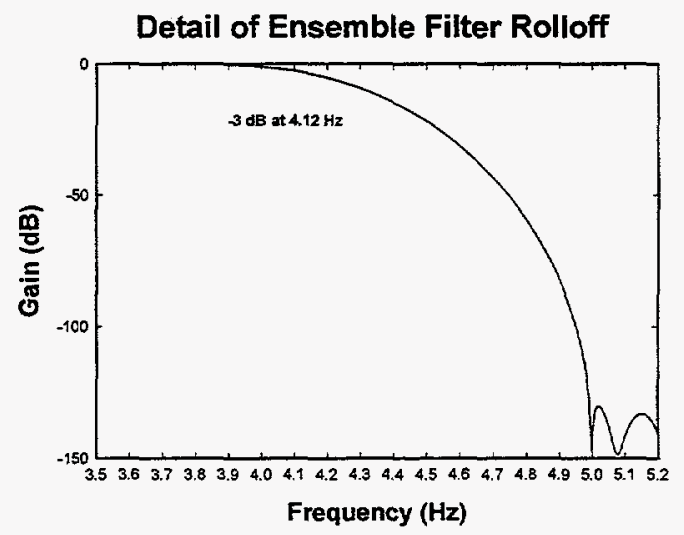

Figure 6 - Ensemble Transfer Function (Detail)

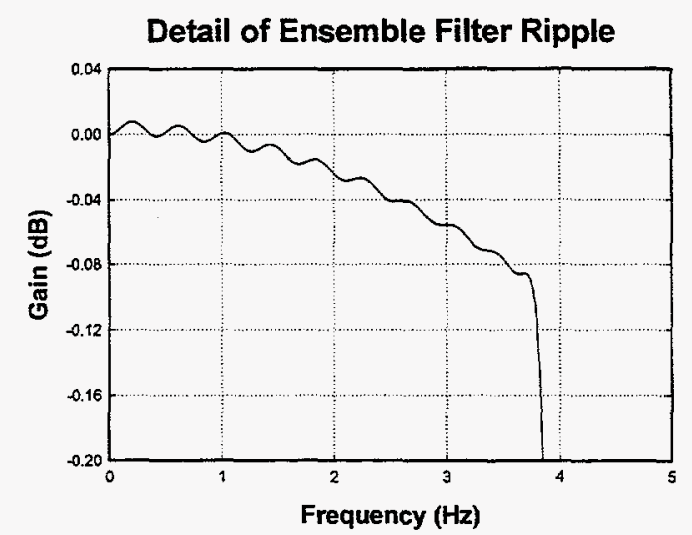

Figure 7 - Ensemble Transfer Function (Detail) 
A FORTRAN program which supposedly simulates the operation of the CS5322 digital filter and possibly originated at Crystal was obtained from TBE. I translated this program to $C$ and modified the input bitstream section of the code to agree with my understanding of the way the integrated bitstream for impulses and step functions would appear. The resulting calculated time domain responses are interesting, particularly in the way they are sensitive to the timing of the start of the impulse or step relative to the output sample clock. Figure 8 shows the two responses when the start of the input signal occurs on an output sample clock pulse, and Figure 9 when the input starts halfway between output samples. These are possibly the only cases which result in symmetric responses, as is suggested by Figure 10, which shows the responses for the same signals starting a tenth of the way between output samples. Several other timing situations were examined as well none of these presented a symmetric response.

Next, a measured step function response was compared to the model response. Figure 11 shows the step response obtained from our time tag accuracy tests on the digitizer system. The step input is provided by an independent, external GPS receiver once a minute and the position of the sample on the turn of the minute should be halfway up the rising edge of the step; thus we would expect the step response in Figure 8 to most accurately simulate the operation of the digitizer system under "GPS-locked" conditions. Indeed, the shape of the response in Figure 11 does compare remarkably well to the simulation in Figure 8 - the difference in the level of the responses (counts) is due to different step amplitudes in the two cases.

I should add that I had some concern that the rejection shown by FIR 2 at half the Nyquist frequency was not sufficient to prevent aliasing of frequencies slightly above that limit into the lower half of the Nyquist interval during the decimate-by-2 operation. In other words, I was not convinced that the rejection shown above $5 \mathrm{~Hz}$ in Figure 5 actually applies. A high frequency sweep test set up and conducted by Dick Kromer to check out this possibility proved that any such aliasing was certainly attenuated enough to be beyond the measurement limits of the DR-24. 


\section{Crystal CS5321/CS5322 Chip Set}

for Teledyne Brown Engineering DR-24 Digitizer
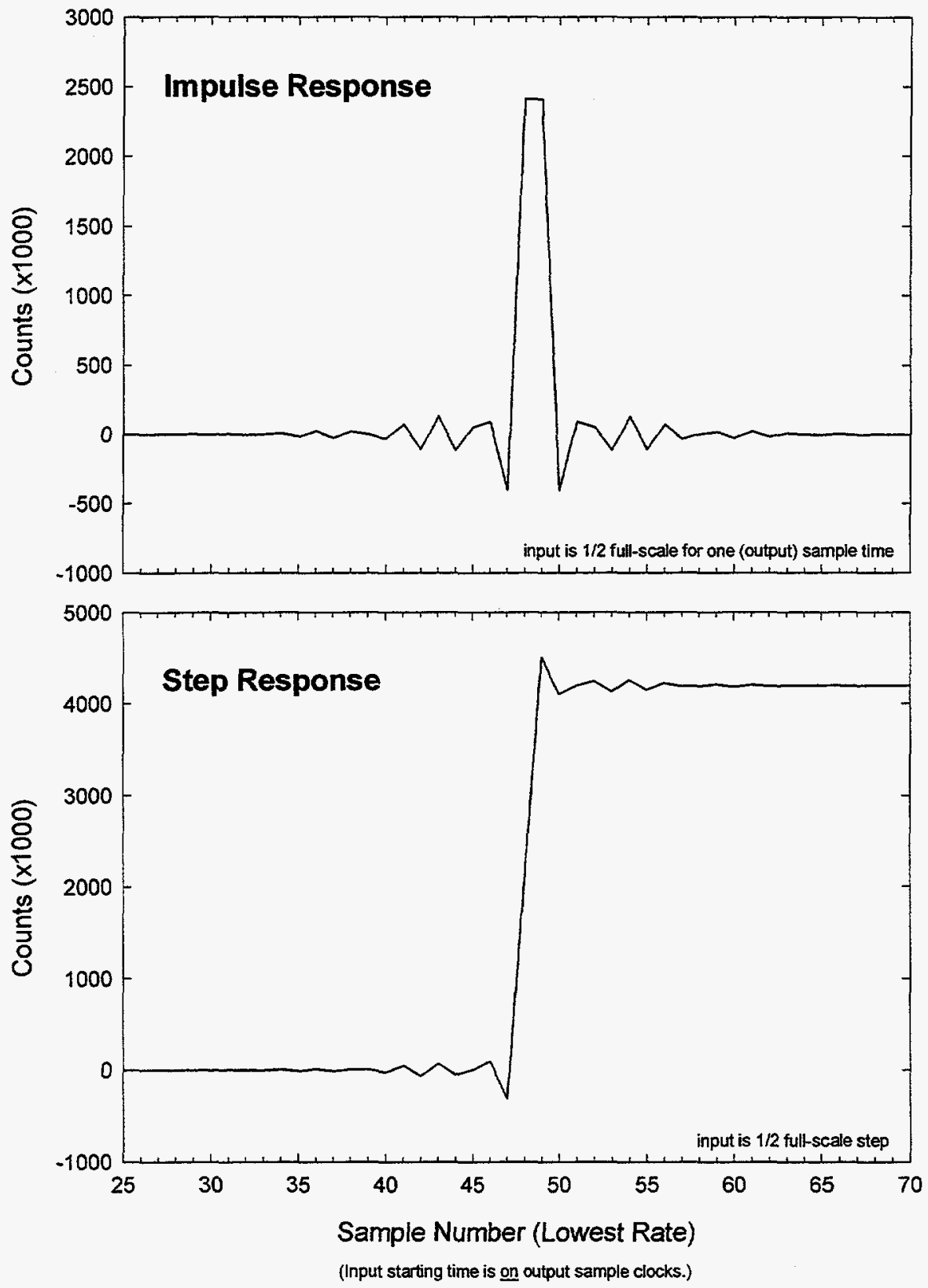

Figure 8 


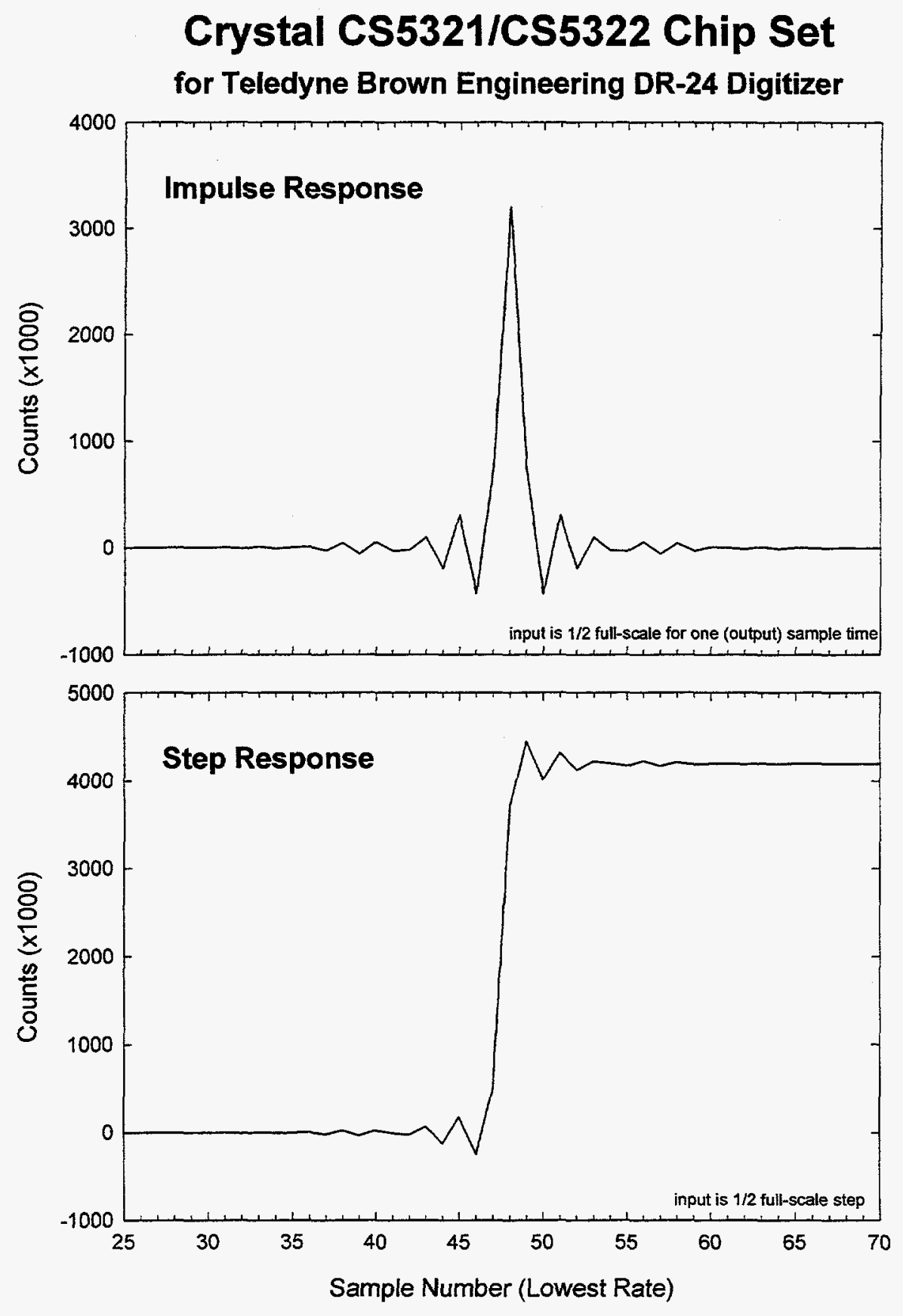

(Input starting time is halfway between output sample clocks.)

Figure 9 


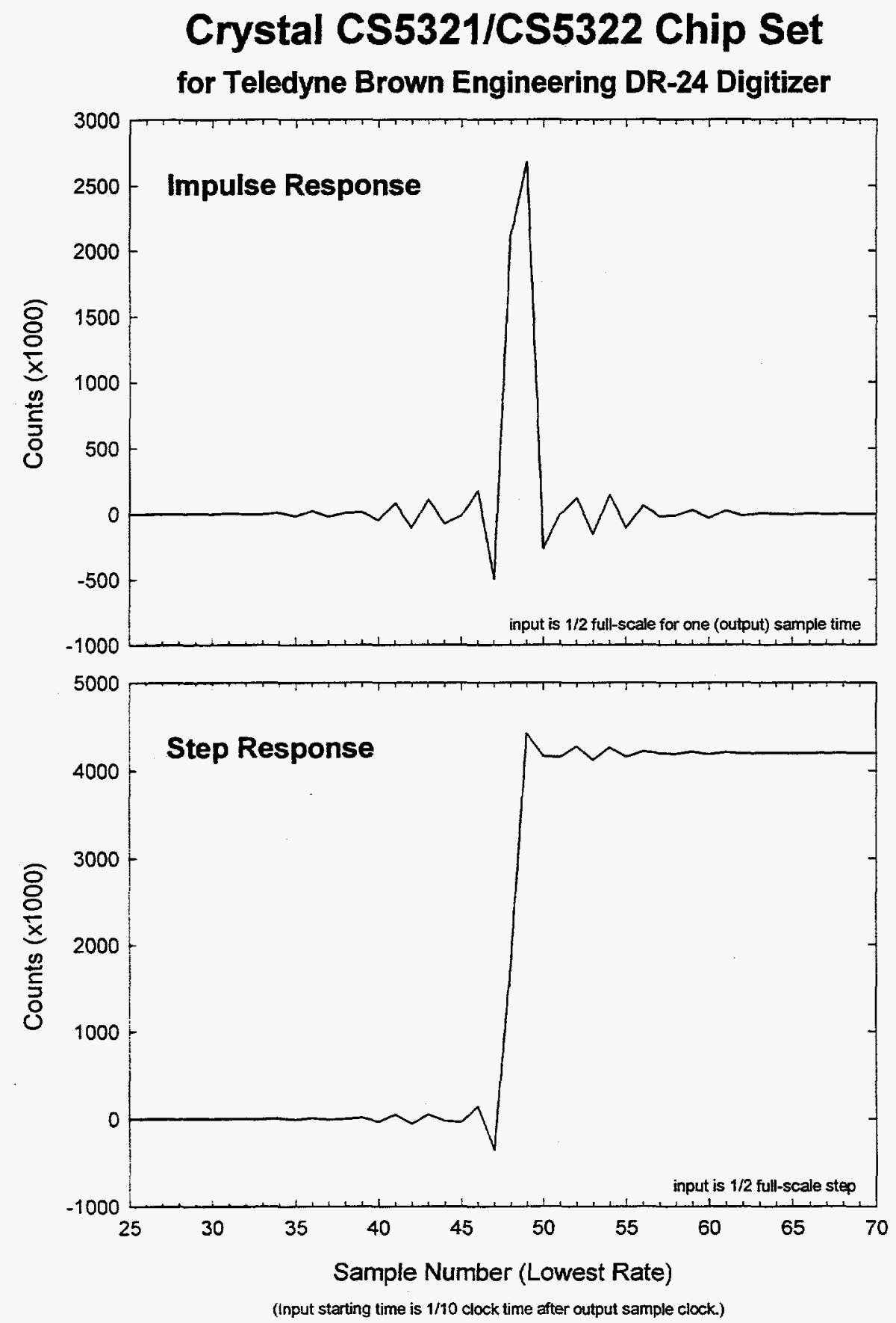

Figure 10 


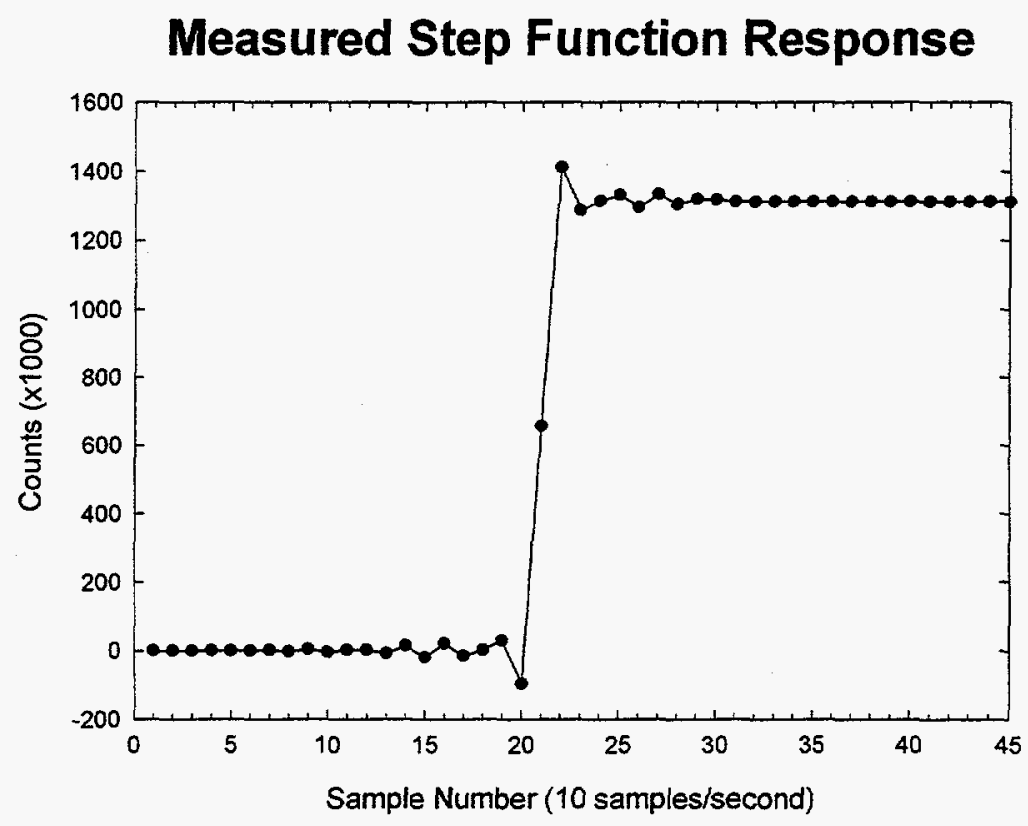

Figure 11

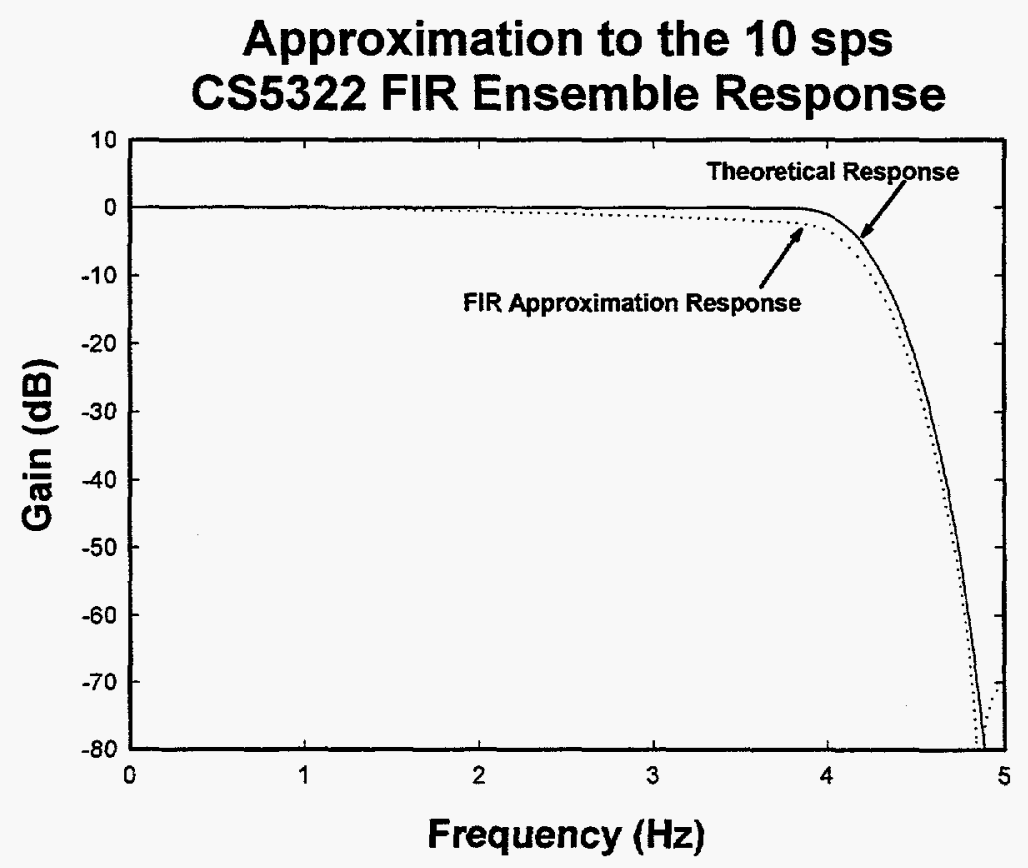

Figure 12 


\section{References:}

1. Crystal Semiconductor Corporation, "CS5321 High Dynamic Range Delta-Sigma Modulator", March 1995.

2. Crystal Semiconductor Corporation, "CS5322 CS5323 24-Bit Variable Bandwidth A/D Converter", March 1995.

3. Crystal Semiconductor Corporation, "The CS5322 Digital Filter", July 1996.

4. Teledyne Brown Engineering - Geotech Instruments, "DR-24 Digitizer Response" (FAX Memorandum from Paul Akers, June 1996).

5. Stearns, Samuel D., Digital Signal Analysis, Hayden, 1975, Chapter 8. 


\section{MEMORANDUM}

Date:

To:

From:

Subject:

Transfer Function
2 October 1997

Dale Breding, SNL 5704

Tim McDonald (API), SNL 5736

Infrasound Sensor/Electronics

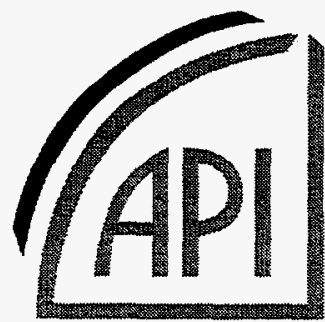

SCIEMTIFIC \& TECHNICAL CONSULT TNTS

The process of converting an infrasound signal into digitizer counts for computer processing involves three transfer functions: that of the sensor itself (pressure into volts), that of the electronic interface (volts-in into volts-out), and that of the digitizer/recording system (volts into counts). The digitizer transfer function for the Teledyne Brown DR-24 is somewhat complicated and was described separately in my memorandum to you on the $4^{\text {th }}$ of September. The other two components, sensor and interface, are described here.

\section{Electronic Interface Response}

We recently obtained the schematic diagram of the infrasound sensor electronics interface along with the electrical component values. This enabled us to verify that the step function response measured last month using a RefTek recorder matched our single-pole model for the interface. As may be seen from Figures 1 and 2, the agreement was remarkably good, especially considering the fact that precision components were not used in assembling the interface.

A few observations concerning the model should be kept in mind:

1. The assumed acquisition system is the RefTek or similar high input impedance waveform recording system. As may be seen in Figure 2, a lower input impedance recorder such as the Teledyne Brown DR-24 reduces the time constant ( $R C$ value) of the response significantly.

2. There actually is another low-pass portion of the electronic interface, but its effect is so limited (time constant of about $5 \mu$ seconds) that it is not included here.

3. The amplitude of the step input for the measured response was not known, at least to us; however, the amplitude of the response suggests that the input step amplitude corresponded to an input signal for 1 Pascal. Since we will be combining the sensor response with the interface response and use an overall sensitivity constant, knowing this step amplitude is really not critical.

4. This high-pass RC filter has the s-plane transfer function:

$$
H(s)=\frac{A s}{s+1 / R C},
$$


where $\mathrm{A}$ is the interface gain constant (it is included as part of the sensor/interface sensitivity value below) and $\mathrm{RC}$ is $97.5 \mathrm{~K} \Omega * 200 \mu \mathrm{F}=19.5$ seconds $^{6}$. Therefore, the model transfer function involves one zero at the s-plane origin and one pole at $-0.051(1 / \mathrm{RC})$ on the s-plane real axis.

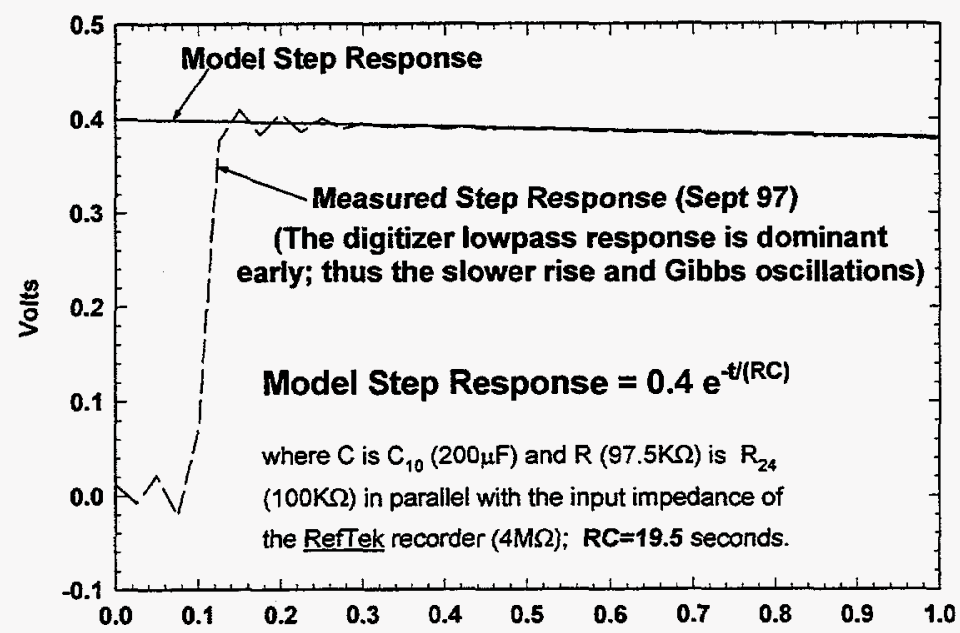

Figure 1 - Electronic Interface Step Response (Early Detail)

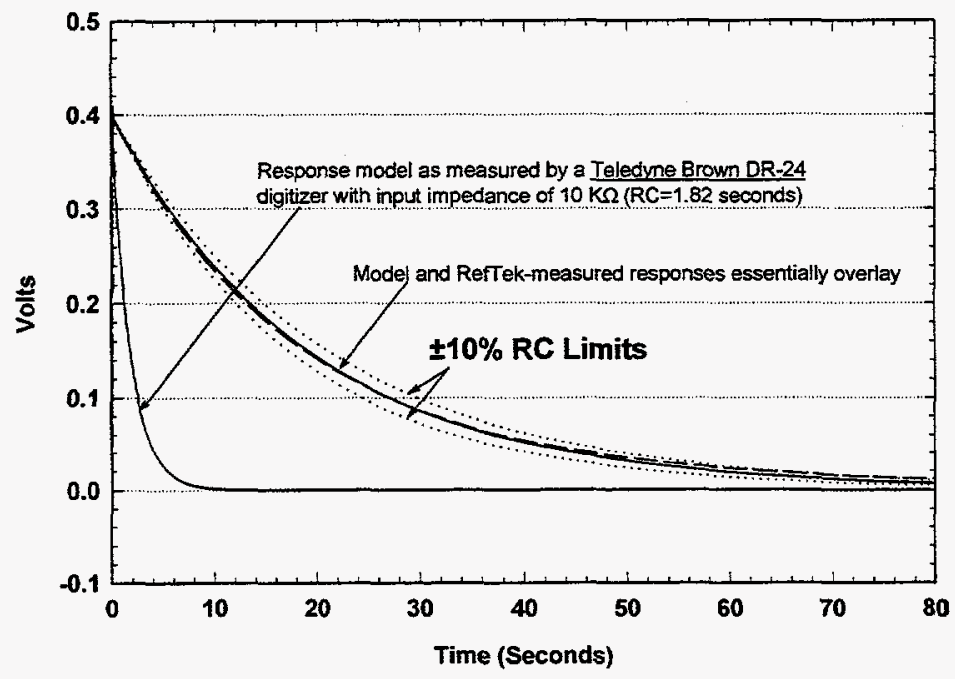

Figure 2 - Electronic Interface Step Response

${ }^{6}$ The $97.5 \mathrm{~K} \Omega$ value is the interface $R_{24}$ specification of $100 \mathrm{~K} \Omega$ in parallel with the RefTek input impedance of $4 \mathrm{M} \Omega$. The $C$ value is the specification for $C_{10}$. 


\section{Sensor Response}

The transfer function for the infrasound sensor was obtained from Appendix A of the reference report, equations $A 10$ to $A 12$, which may be rewritten slightly as

$$
\begin{gathered}
H_{s}(j \omega)=\frac{j \omega a v}{C+j D}, \text { where } \\
C=\frac{a^{2}}{r}-\omega^{2}[R V v+a b R(V+v)] \text { and } \\
D=\omega\left[a^{2} b+a v+\frac{a R(V+v)}{r}\right] .
\end{gathered}
$$

The parameter values for the prototype sensor (see the reference for definitions and units) $\operatorname{are}^{7}$

$$
\begin{aligned}
\mathrm{a} & =1.4 \mathrm{E} 6 \\
\mathrm{~b} & =1.0 \mathrm{E}-4 \\
\mathrm{r} & =10749.5 \\
\mathrm{R} & =0.23 \\
\mathrm{v} & =6435.18 \\
\mathrm{~V} & =4.0 \mathrm{E} 4
\end{aligned}
$$

Using these equations and parameters and substituting $s$ for $j \omega$, we see that the sensor transfer function has one zero at the s-plane origin and two poles, one at -152 and one at -0.02 , both on the s-plane real axis. Note that we need not be concerned with the numerator coefficient, since it will be the sensor / interface combined sensitivity we require, and that will be determined by calibration (nominal is $400 \mathrm{mv} / \mathrm{Pascal}$ ). The shape of the power gain and the phase response for the sensor are plotted in Figure 3.

${ }^{7}$ Values were obtained via personal communication with Rodney Whitaker. 


\section{Chaparral Infrasound Sensor Transfer Function \\ (Case 3 Parameters)}
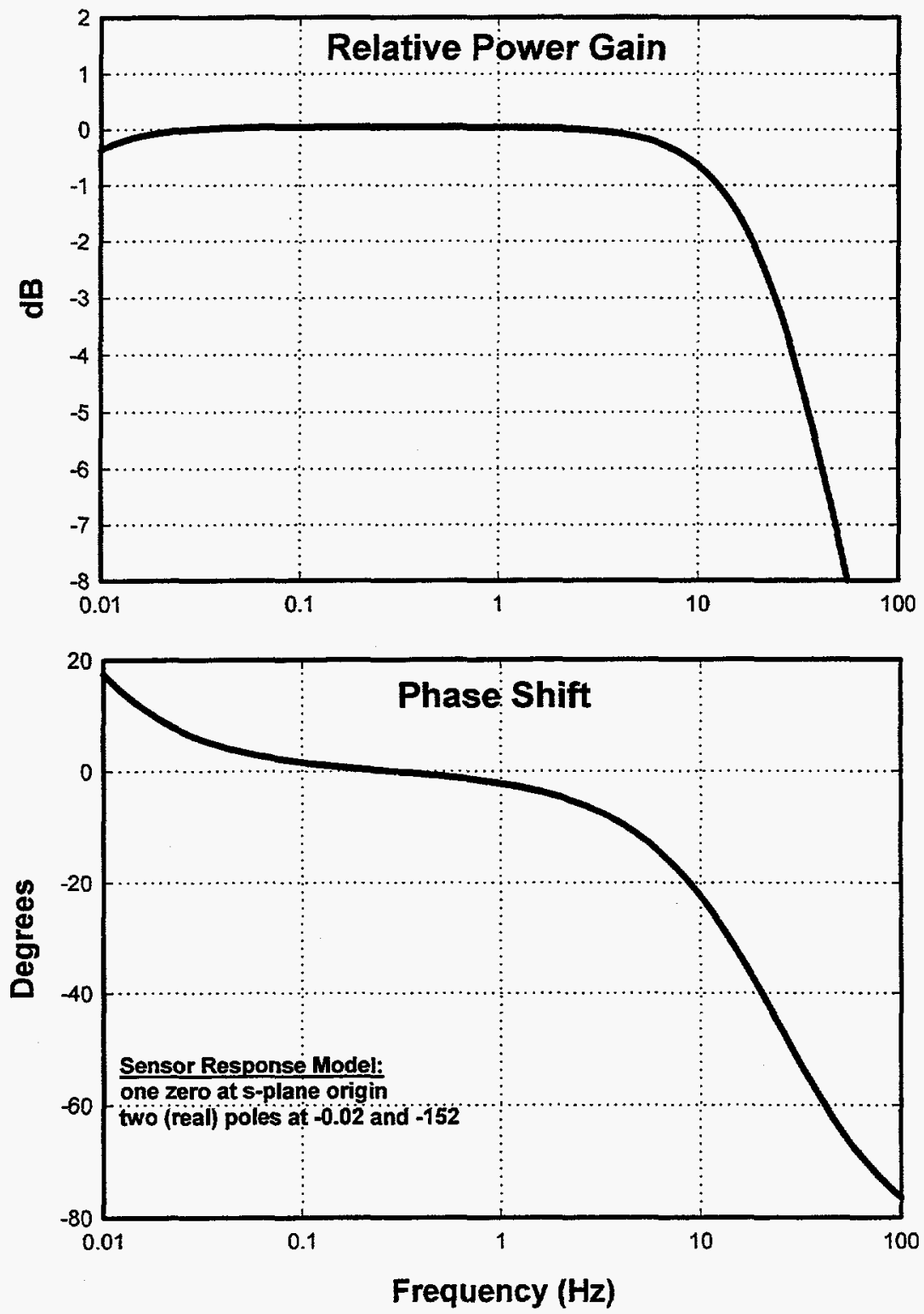

Figure 3 - Sensor Transfer Function

\section{Combined Sensor / Interface Transfer Function}

The combined transfer function is simply the product of the sensor and electronic interface transfer functions. Scaled for the nominal sensitivity in the flat portion of the response(1 $\mathrm{Hz}$ ), the power gain and phase shift are presented in Figure 4. 

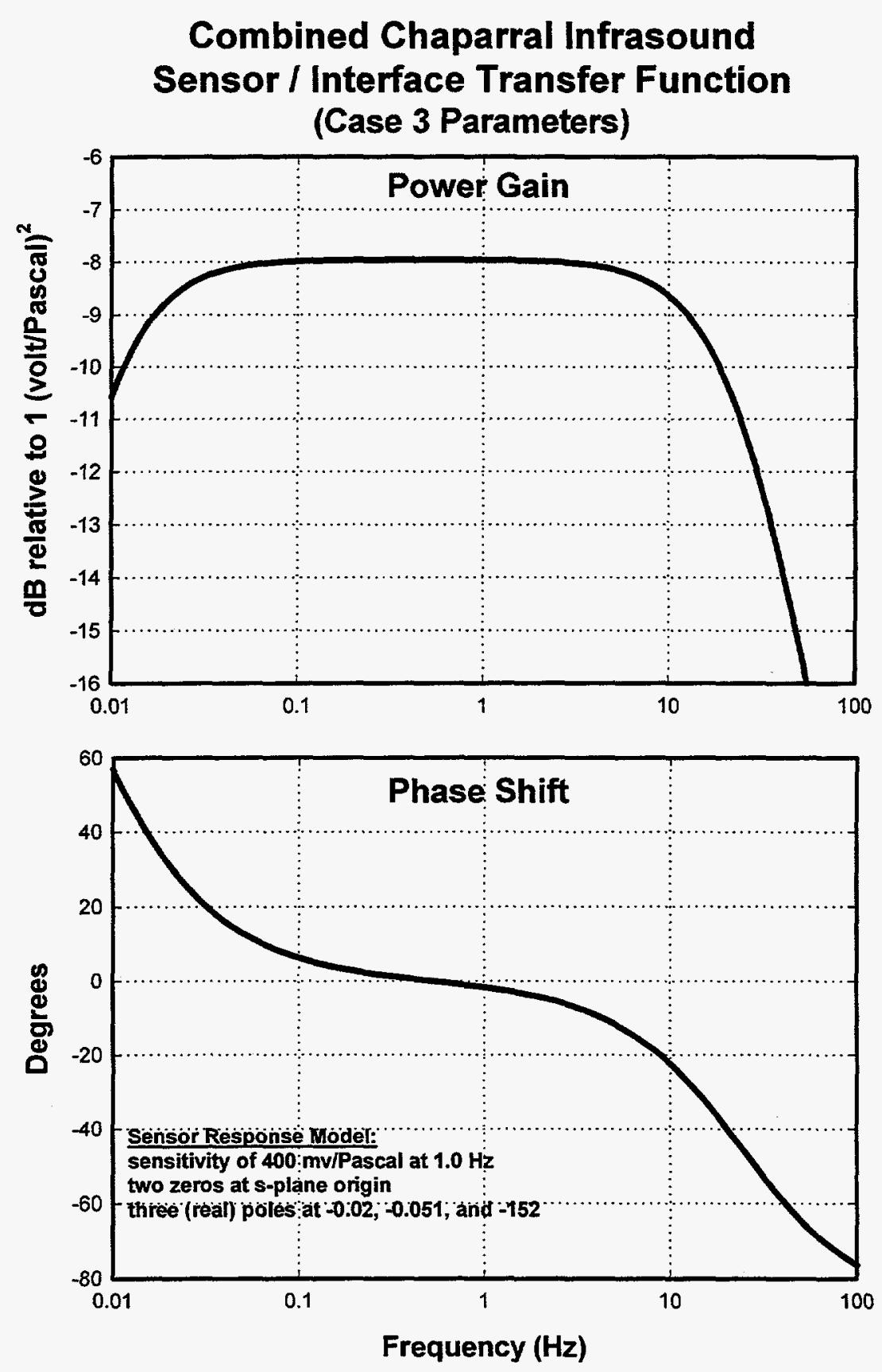

Figure 4 - Combined Transfer Function

\section{Reference}

Mutschlecner, J. Paul and Whitaker, Rodney W., "The Design and Operation of Infrasonic Microphones", Los Alamos National Laboratory, Report LA-13257, UC-706, May 1997. 
Distribution

9 Air Force Technical Applications

Center (AFTAC)

ATTN: Frank Pilotte (TT)

Major Lou Larsen (TTR)

David Russell (TTR)

Carol Finn (TTR)

Dean Clauter (TTR)

Joseph Schrodt (TTR)

Eugene Smart (TTR)

Bruce Varnum (TTD)

Mike Baker (TTS)

1030 South Highway A-1A

Patrick Air Force Base, FL 32925

3 Air Force Technical Applications

Center (AFTAC)/

Command Technologies, Inc.

ATTN: Robert Kemerait

Tom Kelly

John Dwyer

1030 South Highway A-1A

Patrick Air Force Base, FL 32925

1 Air Force Technical Applications/

Center for Monitoring Research

ATTN: Dr. Bob Blandford

Suite 1450

1300 North 17th Street

Arlington, VA 22209

1 U.S. Department of Energy

ATTN: Leslie Casey/NN-20

1000 Independence Ave. SW

Washington, DC 20585-0420

2 U.S. Department of Energy

ATTN: Dorothy Donnelly/NN-1

Josh Segal/NN-42

1000 Independence Ave. SW

Washington, DC 20585
3 DCI/ACIS

ATTN: Larry Turnbull

Tim Murphy

Sean Doran

New Headquarters Building

Washington, DC 20505

3 ACDA

ATTN: Gil Sateia

Nicholas Carrera

Richard Morrow

3020 21st Street, NW

Washington, DC 20451

7 Los Alamos National Laboratory

ATTN: Wendee Brunish, MS F659

David J. Simons, MS D460

Mark Hodgson, MS D460

Craig Pearson, MS C335

Tom Armstrong, MS F659

Paul Mutschlecner, MS F659

Douglas ReVelle, MS F659

PO Box 1663

Los Alamos, NM 87545

10 Los Alamos National Laboratory

ATTN: Rod Whitaker, MS F659

PO Box 1663

Los Alamos, NM 87545

2 Lawrence Livermore National

Laboratory

ATTN: Jay Zucca, MS L-205

Dave Harris, MS L-205

PO Box 808

Livermore, CA 94551

2 Pacific Northwest National Laboratory

ATTN: Dan Hagedorn, MS K5-12

Ray Warner, MS K6-48

PO Box 999

Richland, WA 99352 
3 Provisional Technical Secretariat PrepCom/CTBTO

ATTN: Gerardo Suarez Jose Alberto Veloso

Douglas Christie

Vienna International Centre

PO Box 1200

Vienna, A-1400 Austria

2 Nuclear Treaty Program Office OSD/NTPO

ATTN: Gus Gustafson Todd Main

1901 N. Moore Street, Suite 609

Arlington, VA 22209

1 IRIS/DMC

ATTN: Tim Ahern 1408 NE 45th Street

Seattle, WA 98105

1 Geophysical Services and Products ATTN: Norman H. Routanen 401 Cypress St., Suite 426 Abilene, TX 79604-0768

1 Geophysical Services and Products Dallas Area Office ATTN: John Sherwin 2722 W. Kingsley Garland, TX 75041

3 Teledyne Brown Engineering Geotech Instruments ATTN: Frank Kissinger

Paul Akers

Gary Deboo

10755 Sanden Drive

Dallas, TX 75238-1366
1 MS0655 Pres Herrington, 5736

10655 Dick Kromer, 5736

10788 Richard Craft, 9525

10788 Tim Draelos, 9525

10877 Pat Fleming, 5906

10970 James Kelsey, 5700

$10 \quad 0979$ Dale Breding, 5704

10979 Don Shuster, 5704

10979 Larry Walker, 5704

11138 Ralph Keyser, 6531

19018 Central Tech Files, 8940-2

50899 Technical Library, 4916

20619 Review and Approval Desk, 12690

For DOE/OSTI 